IZA DP No. 10343

Boys Lag Behind: How Teachers' Gender Biases Affect Student Achievement

Camille Terrier

November 2016 


\title{
Boys Lag Behind: How Teachers' Gender Biases Affect Student Achievement
}

\author{
Camille Terrier \\ $M I T, I Z A$ and CEP
}

Discussion Paper No. 10343
November 2016

\author{
IZA \\ P.O. Box 7240 \\ 53072 Bonn \\ Germany \\ Phone: +49-228-3894-0 \\ Fax: +49-228-3894-180 \\ E-mail: iza@iza.org
}

Any opinions expressed here are those of the author(s) and not those of IZA. Research published in this series may include views on policy, but the institute itself takes no institutional policy positions. The IZA research network is committed to the IZA Guiding Principles of Research Integrity.

The Institute for the Study of Labor (IZA) in Bonn is a local and virtual international research center and a place of communication between science, politics and business. IZA is an independent nonprofit organization supported by Deutsche Post Foundation. The center is associated with the University of Bonn and offers a stimulating research environment through its international network, workshops and conferences, data service, project support, research visits and doctoral program. IZA engages in (i) original and internationally competitive research in all fields of labor economics, (ii) development of policy concepts, and (iii) dissemination of research results and concepts to the interested public.

IZA Discussion Papers often represent preliminary work and are circulated to encourage discussion. Citation of such a paper should account for its provisional character. A revised version may be available directly from the author. 


\section{ABSTRACT \\ Boys Lag Behind: How Teachers' Gender Biases Affect Student Achievement ${ }^{\star}$}

I use a combination of blind and non-blind test scores to show that middle school teachers favor girls when they grade. This favoritism, estimated in the form of individual teacher effects, has long-term consequences: as measured by their national evaluations three years later, male students make less progress than their female counterparts. Gender-biased grading accounts for 21 percent of boys falling behind girls in math during middle school. On the other hand, girls who benefit from gender bias in math are more likely to select a science track in high school.

JEL Classification: I21, I24, J16

Keywords: teachers, gender biases, progress, achievement inequalities

Corresponding author:

Camille Terrier

Department of Economics

Massachusetts Institute of Technology

50 Memorial Dr.

Cambridge, MA 02142

USA

E-mail: cterrier@mit.edu

\footnotetext{
* I would especially like to thank my advisor, Marc Gurgand. This paper also benefited from discussions with and helpful comments from Joshua Angrist, David Autor, Esteban Aucejo, Elizabeth Beasley, Thomas Breda, Ricardo Estrada, Victor Lavy, Alan Manning, Eric Maurin, Stephen Machin, Sandra McNally, Steve Pischke, Corinne Prost, and anonymous referees and participants at various seminars and conferences. I am especially grateful to Francesco Avvisati, Marc Gurgand, Nina Guyon, and Eric Maurin for sharing their dataset, as well as to the Direction de l'Evaluation, de la Prospective et de la Performance (DEPP) of the French Ministry of Education for giving me access to complementary data used in this paper. A previous version of this paper circulated as a CEP Discussion Paper no. 1341 - March 2015.
} 
Boys are increasingly lagging behind girls at school. ${ }^{1}$ This disadvantage has important consequences: boys who fall behind are at risk of dropping out of school, not attending college or university, and/or being unemployed. In OECD countries, 66 percent of women entered a university program in 2009, versus 52 percent of men, and this gap is increasing (OECD (2012)). In Europe, 43 percent of women aged 30-34 completed tertiary education in 2015, compared to 34 percent of men in the same age range. Because this gap has increased by 4.4 percentage points in the last ten years, there is a growing interest in identifying its roots. ${ }^{2}$ Some recent studies have highlighted the role of school-related inputs, such as school quality (Autor et al. (2016)), peer socio-economic status (Legewie, DiPrete (2012)), teacher gender (Dee (2005)), or teaching focus on literacy or numeracy (Machin, McNally (2005)).

This article complements this literature by demonstrating how teachers' gender biases affect their pupils' progress and schooling decisions. A number of papers have shown that stereotyping can bias teachers' assessment and grades, but the impact of such biases has yet to be addressed. ${ }^{3}$ Prior research on that topic is limited, and it has focused on specific mechanisms through which a gender bias could affect progress. Research shows that teachers' biases generate self-fulfilling prophecies (Jussim, Eccles (1992)), produce stereotype threats ${ }^{4}$ (Steele, Aronson (1995), Spencer et al. (1999), Hoff, Pandey (2006)), affect students' interest in a subject (Marsh, Craven (1997), Trautwein et al. (2006), Bonesrønning (2008)), and affect students’ levels of effort ${ }^{5}$ (Mechtenberg (2009)). To my knowledge, this is one of the first papers to pro-

\footnotetext{
${ }^{1}$ In OECD countries, "15-year-old boys are more likely than girls, on average, to fail to attain a baseline level of proficiency in reading, mathematics and science" (OECD (2015)).

${ }^{2}$ In France, 49.6 percent of women aged 30-34 have completed tertiary education in 2015, compared to only 40.3 percent of their male counterparts.

${ }^{3}$ See for instance Bar, Zussman (2012), Burgess, Greaves (2013), Hanna, Linden (2012) on teachers' gender bias, and Tiedemann (2000) and Fennema et al. (1990) for the existence of a gender bias in mathematics. Several papers have exploited blind and non-blind scores (teachers' grades) to test the existence of such biases in teachers' grades, a methodology introduced in a seminal paper by Lavy (2008). Some papers find that girls benefit from grade discrimination (Lindahl (2007), Lavy (2008), Robinson, Lubienski (2011), Falch, Naper (2013), Cornwell et al. (2013)), while others find no gender bias (Hinnerich et al. (2011)). Ouazad, Page (2013) and Dee (2007) observed that gender biases depend on teachers' genders. Breda, Ly (2015) found that discrimination depends on the degree to which the subject is "male-connoted".

${ }^{4}$ The latter arises when girls or minority groups perform poorly for the sole reason that they fear confirming the stereotype that their group performs poorly. The apprehension it causes might disrupt women's math performance. Therefore, over-grading girls can reduce their anxiety to be judged as poor performers when they undergo a math exam.

${ }^{5}$ Mechtenberg (2009) provided a theoretical model of how biased grading at school can explain gender differences in achievements. School results are defined as a combination of talent and effort, the latter being the channel
} 
vide empirical evidence on how teachers' gender biases affect pupils' progress and schooling decisions, along with a contemporaneous and independent study by Lavy, Sand (2015). ${ }^{6}$

I use a rich student-level dataset produced by Avvisati et al. (2014) that follows 4490 pupils from grade 6. To quantify teachers' gender biases in math and literacy, I exploit an essential feature of the data: it contains both blind and non-blind scores. An external corrector without knowledge of student's characteristics provides schools with blind scores. These scores are therefore presumably free of teachers' biases. Teachers provide the non-blind scores at the same period for in-class exams. Both scores are designed to measure the same skills-an assumption that I discuss and test in the paper. ${ }^{7}$ In addition, the data allows us to follow pupils over time. The dataset contains blind scores up to grade 9, the high schools attended by each student (general, professional, or technical), and students' course choices during high school (scientific, literature, or social sciences). This gives me the opportunity to study the long-term impact of teachers' gender biases on pupils' progress, schools attended, and course choices.

I start by documenting extensive gender bias in teacher evaluations in grade 6. Following the footsteps of many previous studies, I use a double-difference (DiD) methodology to measure teachers' gender biases (Falch, Naper (2013), Breda, Ly (2015), Lavy (2008), Goldin, Rouse (2000), and Blank (1991)). The gender bias is defined as the average gap between nonblind and blind scores for girls, minus this same gap for boys. ${ }^{8}$ Overall, I find a substantial bias against boys in math, representing 0.3 points of the standard deviation (SD). This tends to confirm existing studies that find that girls are favored by teachers in math (Falch, Naper (2013), Breda, Ly (2015)). However, no gender bias is observed in literacy. Taking boys' more disruptive behavior and students' initial achievement into account does not affect the estimate through which gender grade biases could affect future cognitive achievement.

${ }^{6}$ Lavy, Sand (2015) analyze a similar question, using the conditional random assignment of pupils to classes and the differences in teachers' stereotypical attitudes to identify the effect that teachers' gender biases have on boys' and girls' respective progress.

${ }^{7}$ This dataset also contains extensive information on pupils' disruptive behavior in the classroom, which allows me to disentangle a bias related to gender from a bias related to pupils' behavior.

${ }^{8}$ This double difference can be interpreted as a gender bias in teachers' grades if the blind and non-blind scores measure exactly the same skills. However, if the grades given by teachers measure slightly different skills (homework for instance), for which boys or girls have an advantage, then the double difference should be interpreted more broadly as a bias in teachers' evaluation methods. The correlation between abilities tested by both scores is tested in the paper, and happens to be equal to 1 . 
significantly. Compared to the existing literature that uses this DiD method to measure an average gender bias, I will exploit the variation of the gender bias between teachers.

To identify the impact of teachers' gender biases on pupils' progress, I use a novel identification strategy that rests on both the variation in teachers' gender biases and the quasi-random assignment of students to biased teachers. The identification therefore stems from a comparison of the relative progress of girls (as compared to boys) in classes where the teacher displays a high degree of bias to the relative progress of girls in classes where the teacher is not very biased. I use a simple latent variable model of a student's progress to recover the reduced-form regression. This model aims to highlight the potential sources of endogeneity that could prevent identification. It disentangles the effect of teachers' gender biases on a student's progress from three other elements that might be correlated to both a teacher's gender bias and students' progress: a pupil's achievement, boys' or girls' unobserved characteristics, and teacher quality.

It is key for the identification that the students are quasi-randomly assigned to the teachers with different degrees of bias. I check that students' gender, social background, initial achievement, and grade repetition are uncorrelated to the gender bias of the teachers. I also show that the gender bias I measure with the double-differences methodology does not capture students' unobserved characteristics-such as stress, response to the stakes of the exams, and the competitiveness of the environment-that might be correlated to progress. In addition, to ensure that I disentangle the impact of a teacher's quality from the effect of his/her gender bias, I use a first-difference specification (between boys and girls) that cancels the teacher's effects. Finally, because a gender bias is estimated for each teacher, the number of observations for each estimation is limited. The resulting estimation error would lead to attenuation bias when I use the teacher bias measure in regressions as an explanatory variable for students' progress. To address the sampling error, I use empirical Bayes estimates of teacher gender biases (Kane, Staiger (2002)).

The main finding is that teachers' gender biases have a high and significant effect on boys' progress relative to girls in both math and literacy. ${ }^{9}$ For two classes where the achievement

\footnotetext{
${ }^{9}$ In interpreting the results, I show that my analysis identifies three effects that I cannot completely disentangle: (1) teachers' gender bias in grades, (2) teachers' potentially biased evaluation methods (for instance, some teachers
} 
gap between boys and girls would be identical in 6th grade, quasi-randomly assigning a teacher who is 1 SD more biased against boys in one of the classes decreases boys' progress in that class relative to girls by $0.136 \mathrm{SD}$ in math and by $0.129 \mathrm{SD}$ in literacy. Over the four years of middle school, teachers' gender bias against boys accounts for 21 percent of boys falling behind girls in math. Then, analyzing the effect separately for boys and girls, I find that having a math teacher who is 1 SD more biased against boys does not impact boys' progress, but significantly increases girls' progress. Conversely, a biased literacy teacher does not impact girls' progress, but significantly reduces boys' progress. This interesting difference might be related to gender differences in self-confidence, which could differ by subject.

Moving to outcomes during high school (four years after the bias), I find that having a math teacher who is 1 SD more biased in favor of girls increases girls' probability of selecting a scientific track in high school by 2.7 percentage points compared to boys. Interestingly, without teachers' bias in favor of girls, the gender gap in choosing a science track-a predictor of careers in STEM fields-would be 11.7 percent larger in favor of boys. On the other hand, teachers' gender biases do not impact boys' relative probability to attend a general high school (rather than a professional or technical one) or to repeat a grade. I am also able to rule out some potential mechanisms. Teachers' biases do not have a cumulative effect: being reassigned to the same biased teacher for a second consecutive year does not further impede boys' relative progress. Similarly, teachers' gender biases have no spillover effect: a bias in a given subject does not impact boys' relative progress in other subjects. Finally, as robustness checks, I show that the blind and non-blind scores measure abilities that are very similar and that the time lag between both scores creates an attenuation bias on my estimates.

Taken together, these results build upon an important literature that suggests teachers' grades are biased. My findings confirm the existence of such biases, but more importantly, they highlight the fact that teachers' gender biases can have long-lasting effects on boys and girls' human capital accumulation, and therefore on the evolution of gender inequalities at school and might use more homework as an evaluation tool, and boys and girls might perform differently at homework), and (3) teachers' behavior in class, which might favor girls or boys. I try to disentangle the latter effect by measuring students' progress over a period where they do not interact with the biased teacher. 
in the labor market. From an academic perspective, this article contributes to the recent and growing literature on the impact of teachers' discretion in grading on students' success (Apperson et al. (2016), Dee et al. (2016), and Diamond, Persson (2016)). This paper also contributes, though indirectly, to the literature highlighting the importance of students' non-cognitive skills (Heckman, Rubinstein (2001)). Previous work has focused on the effect of parental inputs on students' non-cognitive skills (Cunha, Heckman (2008)), while this paper focuses on teachers as another potentially key input.

\section{Data}

\section{I.A Dataset}

I consider the question of teachers' assessment biases by using a French dataset that covers 35 middle schools, 191 classes, and 4490 pupils. All students are first observed during grade 6 (11 years old), the first year of middle school. Blind and non-blind scores are available for each student. Students obtain the blind score when they complete a standardized test at the beginning and end of grade 6. The French Education Ministry created this test, taken annually by all French pupils, to assess students' cognitive skills. Identical across all schools, it tests knowledge on literacy (reading and writing) and mathematics. Importantly, this test is externally graded, and graders do not know the names, genders, social backgrounds, or behavior of pupils they evaluate. This blind score can therefore be assumed to be free of any bias caused by stereotypes from an external examiner. Each student also receives grades from teachers on in-class exams. A pupil has a different teacher in each subject, and each teacher reports their pupils' average grades on end-of-term report cards. In this study, I use information on the average grade given by teachers in math and literacy during the first and last terms of grade

6. Because teachers have permanent contact with the pupils they teach, these average grades could potentially be biased by teachers' gender stereotypes.

The standardized test and class exams are designed to measure the same abilities. Appendix A.1 describes abilities measured respectively by the blind and the non-blind scores. Both tests 
are also taken under the same conditions: pupils fill in both tests in their usual classrooms, and their teachers give instructions. Blind and non-blind tests also include questions with different degrees of difficulty. The national evaluation relies heavily on written questions: in literacy, only 18 percent of questions are multiple choice, with the remaining 82 percent requiring written answers. The percentage is even higher in math, where 95 percent of the questions require written answers. The reliance on written questions makes the national evaluation format similar to in-class exams, where multiple-choice questions are quite rare. ${ }^{10}$ This similarity is partly due to grade 6 teachers: 49 percent of literacy teachers and 47 percent of math teachers report using the standardized evaluation provided by the ministry as a benchmark to create their own class exams (French Ministry of Education (2005)). However, despite featuring similar types of questions, the formats of both tests might differ. The standardized test consists of two sessions of 45 minutes over two days, while teachers' assessments of their pupils rely primarily on in-class exams and possibly some home work. The stakes also differ between tests. The standardized tests are not high-stakes for the students. ${ }^{11}$ They are an administrative evaluation aimed at reporting pupils' average achievement by schools to the ministry. Unlike in-class exams, a pupil's result on the standardized test does not factor into his/her end-of-term average score or have a bearing on the grade repeat decision at the end of the year. The effect of these different stakes will be discussed in a further section. This dataset also contains a rich set of measures of grade 6 pupils' disruptive behavior. Records include official "disciplinary warnings", definitive exclusions from school, temporary exclusions from school or class, and detentions. Temporary exclusions signal violent behavior or repeated transgressions of the rules and are decided by the school head. Pupils may accumulate each of these sanctions.

Blind scores and schooling decisions are available several years after grade 6, which enables me to estimate the effect of gender bias on pupils' progress, school choices, and course choices. Pupils receive blind scores at the beginning of grade 6 , at the end of grade 6 , and at end of grade 9. The test completed at the end of grade 6 is extremely similar to the one pupils take when they

\footnotetext{
${ }^{10}$ Machin, McNally (2005) suggested that the mode of assessment could affect the gender achievement gap.

${ }^{11}$ For teachers, their evaluations or salaries do not depend on their pupils' results on standardized tests, so they have no incentive to "teach to the test".
} 
enter grade 6. Both the beginning and end-of-year exams test similar knowledge and are created by the French Education Ministry, are identical across schools, and are externally graded. Then, at the end of grade 9 (which is also the end of middle school), all pupils take a national exam to obtain the Diplome national du brevet. This externally graded score constitutes the final blind measure of pupils' ability in middle school. ${ }^{12}$ The dataset also includes information about pupils' choice of high school and course choices in high school. After students complete middle (and compulsory) school in grade 9, they must choose between general, vocational, or technical training. Pupils who decide to follow general training have to specialize when they enter grade 11 by choosing sciences, humanities, or economics and social sciences. I use this information to estimate the effect of teachers' gender biases on four outcomes: pupils' probability of undergoing general training, likelihood to follow scientific courses, likelihood to follow literature courses, and likelihood to repeat a grade. Information on pupils' longterm outcomes comes from the statistical department of the French Ministry of Education. An analysis of attrition is done in section IV.E. Overall, 18.9 percent of the literacy scores and 19.6 percent of the math scores are missing at the end of grade 9. We also do not have information on grade 11 course choices for 20.9 percent of pupils.

Finally, the dataset contains information on teachers' genders, birth dates, and years of experience, as well as administrative information on children: gender, parents' professions, grade retention, and birth date. The schools included in this dataset are mostly located in deprived areas. Therefore, they are not completely representative of all French pupils, an issue that I will discuss in a further section.

\section{I.B Descriptive Statistics}

The first column of Table 1 presents descriptive statistics for all students, while the next columns compare the characteristics of boys and girls. 48.1 percent of the pupils are girls, and 68.6 percent of them have low SES parents, which is consistent with most schools located in the deprived administrative area of Creteil. In grade 6, 50 percent of math teachers and 85

\footnotetext{
${ }^{12}$ Unlike the grade 6 blind scores, the grade 9 blind scores are high-stakes for the pupils.
} 
percent of literacy teachers are female. Forty-five percent of students in the dataset attended a general high school in grade 10, but this percentage is higher for girls (50.9 percent) than for boys (40.3 percent). Around 16 percent of the sample attended the scientific track of a general high school in grade 11. A detailed analysis of attrition is presented in Section IV.E. In the sequel, all test scores are standardized - the mean equals zero and the variance equals one. Standardization is done within score (blind and non-blind), subject, and term.

Graphics 1 and 2 display distributions of blind and non-blind literacy scores at the beginning of grade 6. Girls strongly outperform boys in this subject, and this premium is not affected by the nature of the grade (blind or non-blind). As reported in Table 1, girls' average score is 0.434 points higher than boys when the score is blind and 0.460 when it is non-blind. However, the story is different in mathematics. Figures 3 and 4 show that boys outperform girls when grades are blind, but the opposite is observed when teachers assess their pupils: girls' average score at the beginning of grade 6 is 0.147 points lower than boys when the score is blind, but it is 0.170 points higher when it is non-blind. Graphically, girls' score distribution clearly shifts to the right of boys' distribution when comparing blind and non-blind scores in math. These distributions are reflective of the difference-in-difference (DiD) methodology that is widely used to measure gender bias in teachers' grades: boys and girls might perform differently, but if the achievement gap is systematically stronger in favor of girls when the grades are nonblind, this higher achievement gap is interpreted as a gender bias in teachers' grades in favor of girls (or equivalently, a bias against boys). The assumptions underlying this methodology will be detailed in a further section.

Figures 5 and 6 plot the distribution of boys' and girls' progress over middle schoolbetween the beginning of grade 6 and the end of grade 9 . I define progress as the difference between the blind score at the end of grade 9 and the blind score at the beginning of grade 6. Because both scores are standardized, a student's progress corresponds to a higher ranking over time in the score distribution. Graphically, there is clear evidence that boys progress less than girls in mathematics, whereas progress in literacy is similar. ${ }^{13}$ Since girls' blind scores

\footnotetext{
${ }^{13}$ At the beginning of grade 6 , girls' average math score is 0.075 points below the mean. It is only 0.021 points below the mean at the end of the 6th grade, and becomes 0.029 points above the mean by the end of grade 9 , hence
} 
were lower than boys' at the beginning of grade 6, the faster progress experienced by girls reduces the gap between boys' and girls' blind scores. By age 15, girls catch up with and even overtake boys in both math and literacy. One of the objectives of this paper is to determine if teachers' biased behavior against boys can explain part of this differential progress in math and the observed inequalities in choosing high schools and STEM courses.

\section{Model of Pupil's Progress}

I define a simple model aimed at isolating the effect of teachers' gender biases on pupils' progress. The main issue when evaluating the impact of grade biases on a pupil's progress is disentangling the effect of grade biases from several other determinants that might explain a pupil's progress and might be correlated to a teacher's biased behavior. The following model aims at isolating these various determinants of a pupil's progress.

Equation 1 describes a blind score $B_{1 i}$ given at the beginning of a period. The term blind refers to a score given by an evaluator who has no identifying information about the student, so the score should not be affected by any teacher's stereotypes. This score is a noisy measure of a student's ability $\theta_{1 i}$. $\epsilon_{B 1 i}$ captures the measurement error. Equation 2 describes a blind score given to the same student at the end of the period. For the remainder of the model, all variables and parameters referring to the end of the period are indexed by 2 . A biased grade is modeled as the difference between a student's ability $\theta_{i}$ and the non-blind grade $N B_{i}$ given by the teacher. At this stage of the model, a biased grade does not refer to a gender bias. It might correspond to a teacher's tough or lenient grading practice that applies to both genders.

$$
\begin{gathered}
B_{1 i}=\theta_{1 i}+\epsilon_{B 1 i} \\
B_{2 i}=\theta_{2 i}+\epsilon_{B 2 i} \\
\text { Bias }_{i}=N B_{i}-\theta_{i}
\end{gathered}
$$

a total increase of 0.104 points of the SD. 
A pupil's ability has changed between the beginning and end of the period. I model this evolution $\theta_{2 i}-\theta_{1 i}$ as a function of the different effects I want to disentangle:

$$
\theta_{2 i}-\theta_{1 i}=\beta \text { Bias }_{1 i}+\eta G_{i}+\mu_{i} T_{i}+\gamma \theta_{1 i}+\omega_{i}
$$

Bias $_{1 i}$ is the difference between a pupil's ability and the grade given by the teacher. ${ }^{14} T_{i}$ is a teacher effect. Teachers' quality (also referred to as their value added) is intuitively correlated to a student's progress. In addition, the best teachers might also be more prone to encouraging girls (or boys), so that teachers' quality and gender biases would not be separately identified. Including a teacher effect in the model allows us to disentangle a teacher effect from the gender bias effect.

$\theta_{1 i}$ is a pupil's achievement. A pupil's initial level might be correlated to both his/her progress and a teacher's discriminatory behavior. Because low achievers have more room for improvement, they might have a higher propensity to progress than their high-achieving counterparts. In addition, pupils' achievement could be correlated to teachers' gender biases. Table 1 shows that girls perform worse than boys in the blind national evaluations in math. If teachers try to encourage low performers by giving them relatively better grades, a bias in favor of girls could partly capture this bias in favor of low performers. In that case, pupils' achievement would be correlated to both teachers' biases and pupils' progress. Failure to take this into account might bias the estimate of the effect of teachers' biased behavior on pupils' progress.

$G_{i}$ is a dummy variable for girls. Girls' unobserved characteristics should be taken into account, as these characteristics might be correlated to both teachers' gender biases and to their progress: girls might have an intrinsic tendency to progress more than boys over the school year, independent of any gender bias.

\footnotetext{
${ }^{14}$ The coefficient $\beta$ captures several channels through which grade biases can affect a pupil's progress. Motivation or discouragement are direct channels, but effort is also an important channel, as are changes in selfconfidence and the reduction of stereotype threats. I will not be able to distinguish between these different channels, which are all captured by the coefficient $\beta$.
} 
A pupil's progress is measured by the evolution of his/her blind score over time :

$$
\begin{aligned}
B_{2 i}-B_{1 i} & =\theta_{2 i}+\epsilon_{B 2 i}-\theta_{1 i}-\epsilon_{B 1 i} \\
& =\beta \text { Bias }_{1 i}+\eta G_{i}+\mu_{i} T_{i}+\gamma \theta_{1 i}+\omega_{i}+\epsilon_{B 2 i}-\epsilon_{B 1 i}
\end{aligned}
$$

$\theta_{1 i}$ is replaced by $\left(B_{1 i}-\epsilon_{B 1 i}\right)$, which gives the following reduced-form equation:

$$
B_{2 i}-B_{1 i}=\beta\left(N B_{1 i}-B_{1 i}\right)+\eta G_{i}+\mu_{i} T_{i}+\gamma B_{1 i}+\pi v_{i}+\epsilon_{B 2 i}+(\beta-1-\gamma) \epsilon_{B 1 i}+\omega_{i}
$$

This equation isolates the different determinants of a pupil's progress. The interpretation of the coefficient $\beta$ is straightforward: once controlled for a pupil's ability $B_{1 i}$, girls' tendency to progress $G_{i}$ and teacher quality $T_{i}, \beta$ captures the effect of receiving a grade that is higher than expected by a pupil's ability.

However, there are two reasons why this individual-level equation is not the specification I estimate. Firstly, and most importantly, the term $\left(N B_{1 i}-B_{1 i}\right)$ captures a bias in teachers' grades, but not a gender bias. Secondly, the estimate of its coefficient $\beta$ would suffer from three sources of endogeneity. An issue of reversed causality exists if teachers tend to be biased in favor of the students they expect to have the highest potential for progress. In addition, because the blind score is a noisy measure of a student's ability, $B_{1 i}$ is correlated to the error term $\epsilon_{B 1 i}$. This measurement error would yield an attenuation bias on $\beta$. Finally, the teacher effect $T_{i}$ might be correlated to the difference $N B_{1 i}-B_{1 i}$ if the best teachers tend to have more tough or lenient grading practices, for instance.

To obtain an estimate of teachers' gender biases and circumvent the endogeneity concerns, I use an alternative specification that consists of aggregating Equation 6 at the class level, for both girls (G) and boys (B), and using a first-difference specification (between boys and girls). The equation below, specified at the class level, corresponds to that new specification, which I use to identify the effect of teachers' gender biases on girls' relative progress. The dependent 
variable is the gap between girls' and boys' progress in class $C:{ }^{15}$

$$
\left(\left(B_{2 G}-B_{2 B}\right)-\left(B_{1 G}-B_{1 B}\right)\right)_{c}=\eta+\beta\left[\left(N B_{1 G}-B_{1 G}\right)-\left(N B_{1 B}-B_{1 B}\right)\right]_{c}+\gamma\left(B_{1 G}-B_{1 B}\right)_{c}+\left(\omega_{G}-\omega_{B}\right)_{c}
$$

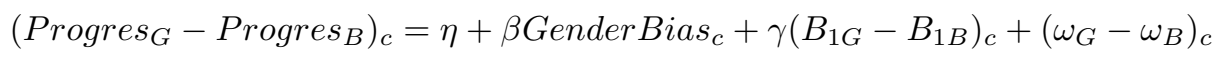

Thanks to the first-difference specification used, the simple difference $\left(N B_{1 i}-B_{1 i}\right)$ becomes a double difference $\left(N B_{1 G}-B_{1 G}\right)-\left(N B_{1 B}-B_{1 B}\right)$, a frequent measure of gender biases in teachers' grades that has been introduced graphically in section I.B (Lavy (2008), Falch, Naper (2013), Breda, Ly (2015), Goldin, Rouse (2000)). The gender bias is the difference between girls' and boys' gap between the average non-blind and blind score. ${ }^{16}$ The assumptions behind this methodology are provided in the next section. In this new aggregated specification, the coefficient $\beta$ identifies the effect of having a gender-biased teacher on girls' relative progress.

The aggregation and first-difference specification also allows us to rule out the three endogeneity concerns observed in the individual-level specification. Because Equation 7 is specified as a differentiation between boys' and girls' average scores at the class level, teacher effects disappear as long as they are assumed to similarly affect boys and girls within a class. The firstdifference specification ensures that the effect of the gender bias I estimate is not explained by a correlation between teachers' value added and their biased behavior against boys. Using a specification based on aggregated variables at the class level instead of at the individual level also helps solve the measurement error concern on $B_{1 i}$. Averaging scores at the class level sig-

\footnotetext{
${ }^{15}$ All variables are averaged conditionally to being a girl and having teacher $T_{i}$. Within a class, girls' average progress is given by:

$$
\begin{aligned}
& E\left(B_{2 i}-B_{1 i} / T_{i}, G_{i}=1\right)=\gamma E\left(B_{1 i} / T_{i}, G_{i}=1\right)+\beta E\left(N B_{1 i}-B_{1 i} / T_{i}, G_{i}=1\right)+\eta E\left(G_{i} / T_{i}, G_{i}=1\right) \\
& \quad+\mu_{i} E\left(T_{i} / T_{i}, G_{i}=1\right)+E\left(\omega_{i} / T_{i}, G_{i}=1\right)+E\left(\epsilon_{B 2 i} / T_{i}, G_{i}=1\right)+(\beta-\gamma-1) E\left(\epsilon_{B 1 i} / T_{i}, G_{i}=1\right)
\end{aligned}
$$

Replacing $G_{i}=1$ by $G_{i}=0$ in the above equation gives the symmetrical equation for boys. To simplify notations:

$$
\begin{gathered}
B_{2 G}=E\left(B_{2 i} / T_{i}, G_{i}=1\right), B_{2 B}=E\left(B_{2 i} / T_{i}, G_{i}=0\right) \ldots \\
\omega_{G}=E\left(\omega_{i} / T_{i}, G_{i}=1\right)+E\left(\epsilon_{B 2 i} / T_{i}, G_{i}=1\right)+(\beta-\gamma-1) E\left(\epsilon_{B 1 i} / T_{i}, G_{i}=1\right) \\
\omega_{B}=E\left(\omega_{i} / T_{i}, G_{i}=0\right)+E\left(\epsilon_{B 2 i} / T_{i}, G_{i}=0\right)+(\beta-\gamma-1) E\left(\epsilon_{B 1 i} / T_{i}, G_{i}=0\right)
\end{gathered}
$$

${ }^{16}$ It should be noted that this model refers to teachers' biases related to students' genders, but the same model could be used to study other sources of bias, such as those related to students' social backgrounds or ethnicity.
} 
nificantly reduces the measurement error affecting blind score measured at the individual level. Finally, aggregation at the class level rules out concerns of a reversed causality at the individual level. Aggregation is, however, not sufficient, as reversed causality might also exist at the class level. An additional assumption is required to rule out the latter: the assignment of pupils to gender biased teachers must be "as good as random," so that the students with an ex-ante high potential for progress are equally distributed between classes. I test this assumption in the section discussing the identification.

Grouped least square (GLS) on a set of class-aggregated means is equivalent to two-stage least-squares (2SLS) using the interaction between teacher and girls as dummy instruments for the gender bias in each class (Angrist, Pischke (2008)). As a result, standard instrumental variables assumptions apply. In particular, a central assumption of the identification-that pupils' assignment to a gender biased teacher is random-will be analogous to an exclusion restriction on these instruments. 2SLS appealing properties also apply to GLS. It notably provides estimators that are robust to measurement error in explanatory variables (Angrist (1991)).

\section{Measuring Gender Biases in Teachers' Grades}

\section{III.A Double-Difference Methodology}

As stated in the previous section, using an aggregated and first-difference specification brings out a double difference, which has been used in prior literature to measure gender biases in teachers' grades. Although the identification in this paper exploits the heterogeneity of this gender bias across teachers (and not its average value), it is important to know if teachers tend to favor a gender on average because it sheds light on the different patterns of progress between boys and girls.

The double-difference methodology was introduced in a seminal paper by Blank (1991) and used by Lavy (2008) to identify a bias in teachers' grades. Later papers have also used this double difference to estimate a gender bias: Falch, Naper (2013), Breda, Ly (2015), and Goldin, Rouse (2000). The strategy consists of estimating the difference between boys' and girls' 
average gap between a non-blind and a blind score $\left(N B_{i 1}-B_{i 1} \mid G_{i}=1\right)-\left(N B_{i 1}-B_{i 1} \mid G_{i}=0\right)$. In the absence of teachers' biases in grades, and under the assumption that both tests measure the same abilities, the difference between the non-blind score and the blind score should be the same for boys and girls: this corresponds to the common trend identification hypothesis. The gender bias is estimated thanks to the following standard double-differences equation:

$$
N B_{i}-B_{i}=\alpha_{0}+\alpha_{2} G_{i}+\epsilon_{i}
$$

$N B_{i}$ is the non-blind score, $B_{i}$ is the blind score, $G_{i}$ is a dummy for girls, and $\epsilon_{i}$ is an individual shock. The coefficient $\alpha_{2}$ provides an estimation of the gender biases in teachers' grades and is equivalent to the double difference presented above and in Equation 7.

This coefficient can be interpreted as a gender bias in teachers' grades if the blind and the non-blind scores measure exactly the same skills, and if students' unobserved characteristics (such as stress) are equally shared by boys and girls. If the grades given by teachers measure slightly different skills (homework for instance), for which boys or girls have an advantage, then the double-difference should be interpreted more broadly as a bias in teachers' evaluation methods. Both assumptions are tested in further sections.

Finally, a last concern for the identification arises if the blind scores are not perfectly blind. An important assumption for the DiD methodology is that the blind test scores do not contain indications of the genders of the students. I cannot completely rule out the fact that some graders might be able to use students' handwriting to determine whether an exam is filled out by a boy or a girl. But if the external correctors can identify a pupil's gender, and if they suffer from the same biases as teachers, the difference between the blind and the non-blind exam would be attenuated. As a result, the DiD results I present in the next section would be a lower bound. 


\section{III.B Estimation of Teachers' Gender Biases}

A more common formulation of DiD Specification 9 is written below. The estimate obtained for the gender bias $\left(\alpha_{2}\right)$ is identical but equation 10 has the advantage of providing coefficients for the gender effect and the non-blind effect:

$$
S c o_{i n}=\alpha+\beta G_{i}+\gamma N B_{i}+\alpha_{2}\left(G_{i} * N B_{i}\right)+\pi_{c}+\epsilon_{i n}
$$

Here $\mathrm{SCO}_{i n}$ is the grade received by a pupil when the nature of scoring is $\mathrm{n}$ ( $\mathrm{n}=1$ for non-blind and 0 for blind). Hence, for each pupil, this dependent variable is a vector of both blind and non-blind grades received. $G_{i}$ is a dummy variable for girls. $N B_{i}$ is a dummy variable equal to 1 if the score has been given non-anonymously by a teacher. ${ }^{17}$ The coefficient of the interaction term $\left(\alpha_{2}\right)$ identifies a gender bias. Finally, for the results presented next, a class fixed effect $\pi_{c}$ is included in the specification. This fixed effect is important to capture elements affecting grades in a given class, such as teachers' severity, student/teacher ratio, peer effects, or some teachers being better at teaching girls than boys.

Table 2 presents the coefficient estimates of Equation 10. The first column presents the results of the standard DiD specification without control variables. In all specifications, standard errors are estimated with school-level clusters to take into account common shocks at the school level. In math, the coefficient of the interaction term Girl*Non-Blind is high and significant -0.31 points of the SD—meaning that a strong bias against boys exists in this subject. Conditional on blind scores, boys' non-blind scores are on average 6.2 percent lower than girls in math at the beginning of grade 6. In literacy, the coefficient of the interaction term (not shown) is neither high nor significant, meaning that no gender bias is observed in this subject. We should keep in mind that the interpretation of this bias is relative: saying that teachers' grades tend to be biased against boys in math is equivalent to saying that girls benefit from a bias in their favor. In the remainder of the paper, I will sometimes use the term gender bias to refer to the gender bias against boys.

\footnotetext{
${ }^{17}$ Note that $N B_{i}$ becomes a dummy in this specification, while it was a continuous variable (for test scores) in the preceding equations.
} 
These results confirm up to a point what Lavy (2008) observes in his analysis: despite the commonly held belief that girls are discriminated against, the biases observed are in favor of girls. Similarly, Robinson, Lubienski (2011) found that teachers in elementary and middle schools consistently rate females higher than males in both math and reading, even when cognitive assessments suggest that males have an advantage. Contrary to both previous studies, I find a bias only in math and not in all subjects. The results of Breda, Ly (2015) are also consistent with my estimates. They found that discrimination goes in favor of females in more "male-connoted" subjects (e.g., math).

I check how pupils' disruptive behavior, initial achievement, and grade repetition affect the gender bias estimate. Taking this into account is important for the second part of the analysis, as these variables could be correlated to both teachers' gender bias and a student's progress. Results are presented in Appendix B: the gender bias is not explained by boys' more disruptive behavior or by them repeating more grades than girls. However, by running quantile regression, I find that the largest gender bias is observed in the lowest decile of the blind scores (with a coefficient of 0.327), while the smallest gender bias is observed in the highest decile of the distribution (with a coefficient of 0.272). All results presented here are based on blind and nonblind scores given at the very beginning of grade 6 . To test if the gender bias is still observed at the end of the year, I use the blind and non-blind grades given at the end of the school year and replicate the analysis done above. Results are presented in Appendix C. Although the gender bias is slightly smaller during the third term than during the first term, the effect of all control variables remains very similar. Finally, results decomposed by teachers' characteristics are also provided in Appendix D.

\section{Identification Strategy}

The previous section presents estimates of the average value of the gender bias among all teachers. The identification exploits the heterogeneity of this gender bias across teachers. More specifically, the identification strategy is based on the observation that not all teachers are bi- 
ased, and that among teachers who have a biased assessment of boys compared to girls, the degree of the bias also differs across teachers, with some teachers being more biased than others. I take advantage of both this heterogeneity in the degree of the bias and the quasi-random assignment of pupils to teachers with different degrees of bias to test whether classes in which students are randomly assigned a teacher who is highly biased against boys are also the classes in which boys progress less (relative to girls). This identification strategy can be seen as a DiD strategy, where the treatment corresponds to a gender bias against boys in some classes and the outcome is boys' progress compared to girls'.

\section{IV.A Heterogeneity in Teachers' Gender Bias}

A simple visual way to test for the heterogeneity in teachers' biased behavior is to plot this variation in a graph. For each class in the sample, Graphics 7 and 8 display the gender bias coefficient on the horizontal axis and girls' progress relative to boys (during middle school) on the vertical axis. The gender bias coefficient is defined as the double difference presented earlier: the class average difference between the non-blind and the blind scores for girls, minus this same difference for boys. The first noteworthy element is the high variation in the degree of teachers' gender biases. Observing a high variation in literacy is particularly interesting if we keep in mind that, on average, we do not observe any bias against boys or girls in this subject. Despite this null average, the high variation across classes in teachers' biased assessments might affect girls' relative progress in these classes.

On the vertical axis, girls' progress relative to boys is measured as the difference between their blind score at the end of grade 9 and this blind score at the beginning of grade 6 , minus this same difference for boys. Graphically, there is clear evidence of a positive correlation between the degree of teachers' gender bias in favor of girls, and the degree of girls' progress compared to boys'. 


\section{IV.B Quasi-Random Assignment of Students to Biased Teachers}

In Equation 7, the coefficient $\beta$ identifies the effect of being assigned a teacher who is $1 \mathrm{SD}$ more biased against boys on boys' average progress relative to girls' after controlling for the initial achievement gap between boys and girls. This coefficient can be seen as a causal effect under the assumption that boys and girls' assignment to a biased teacher is quasi-random. In other words, being assigned a biased teacher is independent of students' unobserved characteristics that could be correlated to their progress. I use the term quasi-random to describe the fact that pupils' assignment to teachers is not done through a proper lottery. Yet, an arbitrary assignment of girls or boys with high predicted progress to biased teachers is highly plausible. Pupils considered in this study are in grade 6, which is the first year of middle school in France. All students beginning grade 6 were enrolled in a different school the year before. Hence, when deciding the composition of classes, school heads have very little information on these new pupils. In particular, it is highly unlikely that school heads can predict students' progress, and therefore influence their assigned class and teacher. In addition, for school heads to assign the most biased teachers to boys who are likely to progress less than girls, they would need to know who the biased teachers are. This is again very unlikely.

Although it is not possible to test the assumption that pupils are randomly assigned to biased teachers, I check if the assignment to a biased teacher is independent from boys' and girls' observed characteristics. I first regress the gender bias (defined at the class level in both literacy and math) on pupils' gender and find no significant effect: within a school, boys are not more likely than girls to be assigned to math or literacy teachers with a high bias. Then, for boys and girls separately, I successively regress math and literacy teachers' estimated gender bias on the following set of predetermined variables: score at the standardized test taken at the beginning of grade 6, having upper-class parents, having lower-class parents, and having repeated a grade. The coefficients are reported in Table 3. Each cell in the table corresponds to the coefficient of a separate regression. In 13 regressions out of 16, the observed characteristics of boys and girls are independent from being assigned a biased teacher. The only three exceptions do not indicate a clear pattern of selection, which confirms students' quasi-random assignment to 
biased teachers.

The previous test rules out selection on observables. A second way to test the random assignment—which also incorporates unobservable characteristics—is to check if the gender bias of math teachers is correlated to the gender bias of literacy teachers. If teachers are as good as randomly assigned, the biases of literacy and math teachers are expected to be completely independent. I regress the gender bias in math on the gender bias in literacy to test if a betweensubject correlation in pupils' experienced gender biases exists. I run this regression with one observation per class, and I cannot reject the hypothesis that there is no correlation between the biases in both subjects: the coefficient is 0.009 ( $\mathrm{SE}=0.094)$.

\section{IV.C Gender Bias and Students' Unobserved Characteristics}

The previous test is also important to show that the gender bias I measure does not capture students' unobserved characteristics. If the gender bias was incorporating information on students' unobserved characteristics, and if these unobserved characteristics are correlated to a student's progress, I would face an endogeneity issue. For instance, if girls' characteristics (such as test-taking habits, stress, or response to competitiveness ${ }^{18}$ ) tend to affect their blind evaluations negatively, this would increase the double difference measure of the gender bias. However, if these characteristics similarly affect girls' (or boys') evaluations in math and literacy, then we should observe a correlation between the measured bias of math and literacy teachers (teaching the same students). The absence of correlation therefore brings one more piece of evidence on the origin of the gender bias: it seems to be a pure teacher's effect rather than a bias driven by pupils' characteristics.

An additional test can be done to further demonstrate that the gender bias I measure does not capture boys or girls' different unobserved characteristics. As stated above, any of these characteristics that affect students equally in math and literacy will similarly affect the estimate of the gender bias in these two subjects. For instance, in my setting, the competitiveness of the

\footnotetext{
${ }^{18}$ Recent studies suggest that girls tend to be relatively less effective than boys in environments that they perceive as more competitive (Gneezy et al. (2003)), or when the stakes of evaluations are higher (Azmat et al. (2016)).
} 
environment and the stakes of the exams are identical for the math and literacy blind exams. Based on this observation, I use an alternative methodology, based on a triple-difference (Breda, Ly (2015)) rather than a double difference, to measure the gender bias. This methodology is equivalent to implementing a within-gender between-subjects regression. It allows the response to stakes or competitiveness to be distributed differently for boys and girls; however, this response must be constant across subjects within gender. This within-gender between-subjects method also controls for any characteristic specific to boys that potentially affects teachers' biases similarly in all subjects: the fact that boys behave worse, might be less attentive, less serious, and less diligent. As reported in Appendix E, the coefficient for relative bias obtained with this method corresponds to the coefficient in math minus the one in literacy, hence 0.291. This is extremely similar to the DiD estimate, which confirms that the gender bias I measure with the DiD methodology does not capture students' unobserved characteristics.

Finally, even if boys and girls were reacting differently to stress, competitiveness, or the stakes of the exams, this would not affect the estimate of interest (the effect of teachers' gender biases on students' progress), as long as the assignment of boys or girls who are more stressed is quasi-random. The quasi-random assignment, tested in the previous section, helps to rule out any selection pattern on unobserved characteristics.

\section{IV.D Interpretation of the Gender Bias}

In my setting, the blind and the non-blind scores might have different formats. In this paper, blind tests are standardized tests created by the French Education Ministry, while non-blind grades correspond to the average mark given every term by the teacher. Although both are designed to measure the same competencies (as explained when presenting the data), we cannot completely rule out small differences in the content or forms of the exams. In particular, the grades given by teachers might encompass some homework. This would not be an issue if the difference in the evaluation methods (the quantity of homework given) was constant across classes. Having no information on the evaluation practices of teachers, I cannot rule out the fact that some teachers use evaluation methods that focus more on skills at which girls are better 
than boys. Hence, the variation across classes of the double-difference estimate of teachers' biases might capture differences in their evaluation methods.

The gender bias might also capture teachers' biased behavior in addition to their biased grading practices. Teachers who tend to be biased against boys in their grades might also engage in other unobserved classroom practices that make boys less likely to succeed. They might be less encouraging, less friendly, focus less attention on boys, or be more critical. This concern is particularly true when measuring the gender bias at the very beginning of grade 6 and in measuring students' progress during grade 6 (between September and June) because pupils experience the gender bias in grades at the beginning of the year and then potentially experience the biased behavior of their teacher throughout the entire year. A way to disentangle these two effects is to use the bias in grades measured at the end of the grade $6^{19}$-instead of the beginning — and pupils' progress between the beginning of grade 7 and the end of grade 9 . This ensures that the progress is measured over a period when pupils are less affected by the biased behavior of their teacher. Hence, in the forthcoming analysis of student's progress, I use the bias measured at the end of grade 6. This seems preferable, but if a teacher's biased behavior has a persistent effect on students, this solution does not allow us to completely disentangle both effects.

To summarize, the effect of gender bias on progress and other outcomes is likely to capture a bias in teachers' grading practices, but also in their evaluation practices and potentially in their behavior. Even without being able to separately identify these elements, it is interesting to know if teachers' biased evaluation practices—with all the elements they embed-have an impact on boys' progress relative to girls'.

\section{IV.E Balance Check of Attrition}

Three different outcomes are used to estimate the causal effect of teachers' gender biases on students : the blind score at the end of grade 9, the school attended during grade 10, and pupils'

\footnotetext{
${ }^{19}$ Both the blind and non-blind scores have been collected at the beginning of grade 6 , but also at the end of the same academic year.
} 
subject choices during grade 11 . Two types of attrition exist: an attrition at the class level, when scores are missing for all pupils in a class, and an attrition at the individual level, when scores are missing for some pupils within a class. There is no attrition at the class level in my sample: all classes for which the bias is estimated at the end of grade 6 are observed in grades 10 and 11. The second type of attrition exists, but it would only be problematic if student attrition is correlated to the bias of teachers. To test this, I check if the percentage of girls or boys missing in a class is correlated to the degree of bias of their teacher. I regress the percentage of girls missing (per class) on the gender bias. This is done successively for boys and girls. For each gender, six different regressions are run (corresponding to the six columns of Table 4), where each of the potentially missing variables are successively the dependent variable: blind score in literacy and math at the end of grade 9, information on school choice during grade 10, and information on course choice during grade 11. None of the coefficients are significant.

\section{Empirical Results}

\section{V.A Empirical Bayes Estimates of Teacher Bias}

A last concern when estimating measures of teachers' gender biases involves estimation error arising from sampling variation. With small samples, a few students can have a large impact on test scores. In my sample, the average number of students per teacher is 36.3 in math and 31.8 in literacy. At the school level, Kane, Staiger (2002) found that among the smallest schools, more than half (56 percent) of the variance in mean gain scores is due to sampling variation and other non-persistent factors. In the presence of sampling error, the estimated teacher bias $t_{j}$ is the sum of the true teacher bias $\theta_{j}$ plus some error $\epsilon_{j}$, where $\epsilon_{j}$ is uncorrelated with $t_{j}$. The variance of the estimated teacher biases has two components: the true variance of the teacher bias and the average sampling variance. Without accounting for it, the estimation error would lead to attenuation bias when I use the teacher bias measure in regressions as an explanatory variable for students' progress. To address this problem of sampling error, I construct empirical Bayes estimates of teacher gender bias. This approach was suggested by Kane, Staiger (2002) for 
measures of schools' accountability measures. The basic idea of the empirical Bayes approach is to multiply a noisy estimate of each teacher bias by an estimate of its reliability. Thus, less reliable estimates are shrunk back toward the mean $(0$, since the teacher estimates are normalized to be mean 0). Several recent applications have used this methodology to estimate teacher value added (Jacob, Lefgren (2005), Kane, Staiger (2008), Chetty et al. (2014)). For each teacher, the reliability ratio of the noisy estimate of the gender bias is the ratio of signal variance to signal plus noise variance, where the noise corresponds to the squared standarderror of the bias estimate. It is relatively simple to estimate this ratio by using the observed estimation error from each teacher bias estimation. We obtain a measure of the true variance $V(\theta)$ by subtracting the mean error variance (the average of the squared standard errors of the estimated teacher bias) from the variance of the observed bias: $V(\theta)=V(t)-E\left[V\left(\epsilon_{j}\right)\right]$.

$$
R R_{j}=\frac{V(\theta)}{V(\theta)+V\left(\epsilon_{j}\right)}=\frac{V(t)-E\left[V\left(\epsilon_{j}\right)\right]}{V(t)-E\left[V\left(\epsilon_{j}\right)\right]+V\left(\epsilon_{j}\right)}
$$

Finally, I construct an empirical Bayes estimator of each teacher's bias by multiplying the initial bias estimate by an estimate of its reliability: $t_{j}^{E B}=t_{j} * R R_{j}$. After adjusting for estimation error, the standard deviation of teacher bias is 0.047 in math and 0.112 in literacy. Before the shrinkage, these SDs were equal to 0.25 and 0.37 , which shows that most of the variation between teachers in the degree of the estimated bias is due to sampling noise. The adjusted estimators of teachers' gender biases will be used in all forthcoming regressions of students' progress on teachers' biases. Jacob, Lefgren (2005) showed that using the empirical Bayes estimates as an explanatory variable in a regression yields point estimates that are unaffected by the attenuation bias that would result from using standard OLS estimates.

\section{V.B Effect of Teachers' Gender Biases on Progress}

The first regression is based on Equation 7. The double difference on the right-hand side of the equation corresponds to teachers' gender bias estimated class by class. In the following empirical analysis, the coefficient used for the gender bias is obtained by running the regression 
of the difference between the non-blind and the blind score on a dummy for girls and control variables for pupils' blind score, grade repetition, and social background. I control for these variables because they would bias the results if they are correlated to both the gender bias and pupils' progress. The empirical Bayes estimate is used in all regressions. In addition, because the bias variable in this regression is a generated regressor, I correct for the sampling error that affects the standard errors of the coefficient $\beta$ by using a two-step bootstrapping method. ${ }^{20}$

The first set of results is reported in Table 5. The dependent variable is girls' relative progress between the end of grade 6 and the end of grade 9, three years after the gender bias is observed. The explanatory variables are the gender bias of the grade 6 teacher-measured at the end of the year - and the gender achievement gap measured at the beginning of grade 6 . Results reported in column 1 suggest that teachers' gender biases have a high and significant effect on girls' progress relative to boys in both math and literacy. For two classes where the achievement gap between boys and girls would be identical in grade 6, randomly assigning a teacher who is one standard deviation more biased against boys in one of the classes would decrease boys' relative progress in that class by $0.136 \mathrm{SD}$ in math and by $0.129 \mathrm{SD}$ in literacy. The long-term effect observed in literacy is interesting: despite the absence of average bias in teachers' grades, there is an important variation in teachers' biased behaviors, which has an effect on boys' relative progress. We observe that during the four years of middle school, girls catch up with—and even overtake-boys in math and literacy. Building on these results, it would be interesting to see whether this would have still occurred without the gender bias. I show that 21 percent of boys' falling behind girls in math can be ascribed to teachers' gender

\footnotetext{
${ }^{20}$ Two-step estimation methods yield inconsistent estimates of the standard errors in the second-stage regression because they fail to account for the presence of a generated regressor (Pagan (1984) and Murphy, Topel. (1985)). This causes naïve statistical inferences to be biased in favor of rejecting the null hypothesis. To deal with this concern, I use a two-step bootstrapping method to compute the standard errors in all regressions that use the estimated gender bias (Ashraf, Galor (2013)). The bootstrap estimates of the standard errors are constructed in the following manner. First, for each teacher, I draw a random sample of pupils with replacement. The first stage regression is estimated on this random sample, and the corresponding OLS coefficient on teachers' gender bias are obtained. The second-stage regression-based on Equation 7-is then estimated on a random sample of classes with replacement, and the OLS coefficients are stored. This process of two-step bootstrap sampling and least-squares estimation is repeated 1,000 times. The standard deviations in the sample of 1,000 observations of coefficient estimates from the second-stage regression are thus the bootstrap standard errors of the point estimates of these coefficients.
} 
bias against them. ${ }^{21}$

When interpreting the previous coefficients, we should keep in mind that the effect is relative: saying that teachers' gender biases reduces boys' relative progress is equivalent to saying that it increases girls' relative progress. For a matter of consistency, I will systematically use the first construction. As the outcome corresponds to the difference between girls' and boys' progress, the positive coefficient I find could correspond to higher progress for girls than for boys, or a blind score that remains constant for girls over time but decreases for boys (due to their feeling of being negatively discriminated against compared to girls, for instance). As explained in section II, this first-difference specification ensures that my estimates do not capture the effect of teachers' quality, which might be correlated to a teacher' gender bias. It is still interesting to present the results separately for boys and girls, although the specification is a bit less convincing in terms of identification. This helps with answering an important question: does the gender bias help girls or hurt boys? The results suggest that having a math teacher who is one SD more biased against boys does not impact boys' progress but significantly increases girls' progress (coef $=0.124, \mathrm{SE}=0.043)$. On the other hand, in literacy, having a biased teacher significantly reduces boys' progress (coef $=-0.061, \mathrm{SE}=0.042)$ but positively impacts girls' progress (coef $=0.067, \mathrm{SE}=0.042$ ), although the coefficients are not significant. ${ }^{22}$

\footnotetext{
${ }^{21}$ The descriptive statistics presented in Table 1 show that at the beginning of grade 6 , the gap between girls' and boys' blind math scores favors boys and equals -0.147 points of the SD. By the end grade 9 , the achievement gap is in favor of girls and equals - $0.058 \mathrm{SD}$. Over the four years of middle school, this represents a relative falling behind of boys compared to girls of 0.205 SD. The results reported above suggest that going from no gender bias to the average estimate of teachers' bias makes boys progress 0.043 points less than girls.

${ }^{22}$ The differences observed between subjects and genders are consistent with a simple model that would take into account two parameters: (1) the importance attached to grades (assumed to be higher for girls than for boys) and (2) the lack of self-confidence (assumed to be higher in literacy for boys and in math for girls). If students are more impacted by encouragement in a subject where they lack self-confidence, we would intuitively expect a bias in math and literacy to impact boys and girls differently. Indeed, a bias against boys in math would hardly impact boys' performance in math (as they do not attach much importance to grades and do not lack self-confidence in math), but it would strongly boost girls' performance (as they both attach more importance to grades and lack selfconfidence in math). This is what my estimates suggest. On the other hand, a bias against boys in literacy would now impact boys negatively, as they tend to lack self-confidence in that subject, while boosting girls' performance less (as they still attach importance to the grade but do not lack self-confidence in literacy). Again, this is exactly what my estimates suggest.
} 


\section{V.C Effect of Teachers' Gender Biases on Course Choice}

Grade 9 is the last grade of middle (and compulsory) school. After this grade, pupils can choose between a vocational, technical, or general high school. The majority of students select general high school because it provides the most opportunities to continue studies at university. In our sample, 50.9 percent of girls chose a general high school, as did 40.3 percent of boys. This highly unbalanced statistic raises a first question: do teachers' gender biases impact the type of high school boys choose compared to girls? Then, for the pupils who decide to attend a general high school, everyone attends the same courses during grade 10, but pupils have to specialize when they enter grade 11. Three options are available to them: sciences, humanities, or economics and social sciences. In this sample, among girls in general high school, 32.8 percent chose the scientific course, while 40.2 percent of the boys did so. This reversal of the gender probability is striking, as the scientific path is the most prestigious one, and the one that leads to higher education in science, technology, engineering, and math (STEM) fields. These fields of study are highly gender-unbalanced in most countries, which raises a second question: do teachers' gender biases impact the relative probability that girls enroll in scientific courses?

Using the same specification as before, I successively analyze the effect of teachers' gender biases during grade 6 on four outcomes: boys' relative probability to attend a general high school, to choose a scientific course, to choose a literature course, and to repeat a grade. Results are presented in Table 6. All regressions are run on all pupils to avoid any selection effect. For instance, the regression of the probability to choose a scientific course in grade 11 is not conditional on attending a general high school.

I find that being assigned a teacher who is one SD more biased against boys in grade 6 decreases boys' relative probability to attend a general high school (rather than a professional or technical one) by 1.5 percentage points, although that coefficient is not statistically significant. This is true when the bias is in math or in literacy. One of the drawbacks of this analysis is the limited number of observations available, which makes it more difficult to detect an effect. The bootstrap method significantly increases the standard-errors value, so that several coefficients are not significant, despite having a sign that is sensible. For instance, a back-of-the-envelope 
calculation confirms the sign and the size of the effect on boys' relative probability to select a general high school. I find that having a teacher who is 1 SD more biased against boys in math decreases their relative progress by $0.136 \mathrm{SD}$ (Table 5), and a simple regression shows that a one-SD drop in boys' relative achievement at the end of middle school reduces their relative probability to attend a general high school by 20.7 percentage points. By combining these two effects, I get an upper-bound effect of a biased teacher on boys' relative probability to attend a general high school of 0.028 . This is in line with the coefficient I obtain in the first column of Table $6(0.015){ }^{23}$ Knowing that, on average in this sample, boys are 10.6 percentage points less likely than girls to attend a general high school, having a teacher who is one SD more biased against boys would increase this gap by one and one half points (14 percent).

The results reported in columns 3 and 4 suggest that teachers' biases in math positively affect girls' relative probability to choose a scientific course during grade 11. More precisely, having a teacher who is one SD more biased in favor of girls increases girls' probability to select a scientific track by 2.7 percentage points compared to boys. This would reduce by 36 percent the gap between boys' and girls' probability to choose a scientific track, which is initially 7.4 percentage points. This observation is interesting, as the scientific path is the most prestigious one, and the one that leads to higher education in STEM fields. This result is in line with Lavy, Sand (2015), who found that "the estimated effect of math teachers' stereotypical attitude [in favor of boys] on enrollment in advance studies in math is positive and significant for boys (0.093, SE=0.049) and negative and significant for girls (-0.073, SE=0.044)."

It is also interesting to calculate what share of the observed gender gap in scientific course choice is due to the average value of teachers' gender biases in math (estimated around 0.32 points of a SD). Teachers' average biases in math contribute to a reduction of 11.7 percent of the gender gap in scientific course enrollment.

Finally, it is worth noting that the biases of literacy teachers have no impact on girls' relative probability to select a scientific track in grade 11 . Teachers' biases against boys in math and literacy seem to increase boys' relative probability to repeat a grade, although the coefficients

\footnotetext{
${ }^{23}$ I refer to this as an upper bound due to the high endogeneity in the second regression of boys' relative probability to attend a general high school on their relative achievement at the end of middle school
} 
are not statistically significant.

\section{V.D Discussion of Potential Mechanisms}

Spillovers of Teachers' Gender Biases. I test the existence of between-subjects effects to understand if the biases of math teachers can impact the progress of students in literature, and vice-versa. To do so, I estimate the effect of the gender bias in math and literacy simultaneously on boys' relative outcomes. Including both biases in a regression is also a good means to test and confirm that the gender bias of literacy and math teachers are independent. Including the bias in literacy in a regression should not change the effect of the gender bias in math.

Results of the standard specification (without spillovers) are presented in columns 1, 3, and 5 of Table 7. In columns 2 and 4, I regress girls' relative progress in a given subject on both the bias in this subject and the bias in the second subject. The results show a complete absence of spillovers: boys' relative progress in math over middle school is affected by their teachers' biases in math, but not by their teachers' biases in literacy. The reverse is true in literature: boys' relative progress in literature is not affected by their teachers' gender biases in math. The last column reports the result for boys' relative probability to select a scientific track, and again, no spillover is observed. In addition, it is important to notice that, between columns 1 and 2, the coefficient of the bias in math does not change when the bias in literacy is included in the regression, confirming the independence of both variables.

Cumulative Effect over Time of the Gender Bias. Teachers' biases affect boys' relative progress over middle school. In this section, I test if this effect corresponds to a cumulative effect of being assigned a biased teacher for several consecutive years. Pupils assigned to teachers with a higher degree of bias might have a higher probability to be re-assigned the same teacher in later grades. ${ }^{24}$ If this is the case, and if the effect of teachers' gender biases is cumulative over time, the effect I observe would correspond to an additive effect. To test this, I have information on the teacher a pupil is assigned to during grades 6 and 7 . I check if

\footnotetext{
${ }^{24}$ Pupils cannot have the same teachers in earlier grades since grade 6 is the first grade of middle school. All pupils were in a different school the year before.
} 
the probability that a pupil is assigned the same teacher during grade 7 is correlated to his/her teachers' gender biases. ${ }^{25}$ The results suggest that being assigned a grade 6 teacher with a one-SD higher gender bias increases a pupil's probability to be reassigned to the same teacher in grade 7 by 4.1 percentage points in math $(S D=0.004)$, but decreases a pupil's probability by 2.5 percentage points in literacy $(S D=0.05)$. Both coefficients are statistically significant, and the estimates are very similar for boys and girls. Then I check if the effect of the bias is cumulative over the years - in other words, if being reassigned a biased teacher further impedes boys' relative progress. For each class, I calculate the percentage of pupils in the class that are reassigned to the same teacher in grade 7 . I add this variable, and its interaction with the gender bias, to the specification used previously. The results presented in Table 8 clearly indicate that the effect of teachers biases is not cumulative over time: the interaction term added is close to 0 in math and literacy. Being re-assigned the same biased teacher does not further reduce boys' relative progress. This result is not so surprising if we think that students might become aware of the gender biases of their teachers, so that the effect fades out. If effort and achievement are substitutes, boys could even increase their effort once they realize that they perform relatively poorly compared to girls.

Contrast Effects, Stereotype Threat, and Mistrust. Finally, prior research can help to interpret my results. Some papers highlight a "contrast effect" according to which a student's academic self-concept is positively influenced by his or her individual achievement, but negatively affected by other peers' average achievement—usually composed of peers in the classroomsonce controlled for individual achievement (Murphy, Weinhardt (2013), Trautwein et al. (2006), Marsh, Craven (1997)). This helps to explain why a gender bias in a given subject—which is a bonus for girls compared to their male peers-could increase girls' progress in this subject, but reduce boys'. Positively rewarding girls, relative to boys, could also reduce the stereotype threat effect. In situations where stereotypes are perceived as important, some girls have been proven to perform poorly for the sole reason that they fear confirming the stereotypes (Spencer

\footnotetext{
${ }^{25}$ More specifically, I regress a dummy indicating if a pupil has the same teacher during grades 6 and 7 on the gender bias of the grade 6 teacher. This regression is done on a sample of 3761 pupils for which I have information on their grade 7 teacher.
} 
et al. (1999)). If math is perceived by girls as highly affected by teachers' stereotypes, overgrading girls in this subject would be expected to reduce their anxiety of being judged as poor performers, and therefore favor their progress in math. Reversely, if boys become aware of the gender biases of their teachers, they might develop behavior that confirms that bias. Finally, if teachers' gender biases are too obvious during grade 6, boys and girls might increasingly mistrust their grades. Mechtenberg (2009) suggests that girls are reluctant to internalize good grades in math because they believe their grades are biased.

\section{Robustness Checks}

First, I run a placebo test where teachers are randomly assigned to different classes. Running the standard regression with boys' relative progress as a dependent variable in both math and literature gives insignificant coefficients in both subjects (in math: $\beta=-0.032, \mathrm{SD}=0.027$, while in literature: $\beta=-0.019$ and $\mathrm{SD}=0.036$ ).

\section{VI.A Are Both Tests Measuring the Same Abilities?}

As explained in the section on double differences, one of the key assumptions behind the $\mathrm{DiD}$ methodology is that blind and non-blind scores measure the same abilities. If this is not the case, and if boys or girls were more endowed in an ability measured more by the class exam, then the double difference would not capture only teachers' gender biases. It would also potentially capture boys' or girls' particular skills measured by one of the scores (including homework, for instance). As mentioned earlier, the fact that the blind and the non-blind scores do not measure the same skills would not bias my estimate as long as the differences in the abilities measured do not vary between teachers. I have adopted a conservative approach so far by saying that I could not completely rule out that grades given by teachers might encompass slightly different skills from the standardized tests, and that this skill difference might also vary across teachers, with some teachers giving more homework. A way to rule out this concern is to show that grades given by teachers and standardized evaluations are measuring the same skills. 
To do so, I define a simple model that describes how blind and non-blind scores are attributed. The main assumption of this model is that blind scores are free of any bias and measure only a pupil's ability, whereas non-blind scores can be affected by teacher's stereotypes toward boys or girls. Hence, blind scores are modeled as a function of a pupil's ability only:

$$
B_{i}=\theta_{1 i}+\epsilon_{i B}
$$

$\theta_{1 i}$ is a pupil's ability, $B_{i}$ is a noisy measure of a pupil's ability, and $\epsilon_{i B}$ corresponds to an individual random shock specific to blind scores. This might capture any effect that makes a pupil overperform or underperform the day of the exam and can be interpreted as measurement error. Non-blind scores can be affected by teachers' beliefs toward pupils' genders. Hence, they can be modeled as a function of both a pupil's ability and his/her gender:

$$
N B_{i}=\alpha_{0}+\theta_{2 i}+\alpha_{2} G_{i}+\epsilon_{i N B}
$$

$\theta_{2 i}$ is the pupil's ability that is measured by the non-blind test. $G_{i}$ is a dummy variable for girls. $\alpha_{2}$ is the coefficient capturing the potential gender bias. $\epsilon_{i N B}$ is an individual shock specific to grades attributed by teachers. This noise might capture pupils' behavior, for instance. Finally, I allow $\theta_{1 i}$ and $\theta_{2 i}$ to differ, meaning that abilities measured by blind and non-blind scores might differ. The relationship between both abilities can be modeled as follows:

$$
\theta_{2 i}=\rho \theta_{1 i}+v_{i}
$$

$v_{i}$ captures variables that potentially affect ability measured by class exams $\theta_{2 i}$, once controlled for ability measured by blind score $\theta_{1 i}$. Any specific ability measured by class exams but not by standardized tests would be captured by $v_{i}$. The skills measured by blind scores $\left(\theta_{1 i}\right)$ might include pupils' long-term memory and their ability to synthesize knowledge acquired in the last few months, while ability measured by non-blind scores $\left(\theta_{2 i}\right)$ might integrate more short-term skills, such as homework or learning an exercise by heart and replicating it the day 
after for the class exam. ${ }^{26}$ The reduced form of this structural model is obtained by replacing $\theta_{2 i}$ by its formula in equation 13 , and by replacing $\theta_{1 i}$ by $\left(B_{i}-\epsilon_{i B}\right)$ :

$$
N B_{i}=\alpha_{0}+\rho B_{i}+\alpha_{2} G_{i}+\left(\epsilon_{i N B}+v_{i}-\rho \epsilon_{i B}\right)
$$

The DiD specification discussed in Section III rests on the assumption that both tests measure the same abilities. In Equation 15, this is equivalent to $\rho=1$ and $v_{i}=0$. A first way to test if both scores measure the same abilities is to directly estimate the reduced-form Equation 15, in which no restrictive assumption is imposed on abilities, and to verify if the coefficient $\rho$ is significantly different from 1 . If not, both tests can be assumed to measure abilities that are very similar. Due to the measurement error affecting the blind score, an instrumental variable approach is used for this estimation, where the blind score is instrumented by a student's month of birth. The method and results are fully detailed in Appendix F. As reported in Table A.6, the IV coefficient of the blind score ranges from 0.964 in literacy to 1.090 in math. In both cases, I cannot reject the hypothesis that $\rho=1$. This result suggests that the blind and non-blind tests measure skills that are very similar, and hence that using the double-difference methodology provides estimates of the gender bias that do not capture differences in the skills measured. ${ }^{27}$

A second way to test if both scores measure the same abilities is to regress boys' and girls' ranks in the blind score on their ranks in the non-blind score. Intuitively, if the standardized evaluation and the class exams measure the same competencies, we would expect pupils' ranks to be the same for both exams. Running the aforementioned regressions confirms this. For girls, the coefficient of the regression is equal to $1(\mathrm{SD}=0.007)$, suggesting a very high correlation between their ranks in the blind and the non-blind scores. For boys, the estimate equals $0.86(\mathrm{SD}=0.007)$. Using the Spearman's rank correlation leaves the results unchanged. The coefficient equals 0.75 for girls and 0.76 for boys.

\footnotetext{
${ }^{26}$ This way of modeling blind and non-blind scores is highly simplified and relies on two important hypotheses. I suppose a linear relation between non-blind scores, ability, and gender, and I assume that non-blind scores do not depend on blind scores in this specification. This hypothesis is likely to be satisfied in our context because blind tests were not graded by teachers but by independent correctors.

${ }^{27}$ In addition, the IV estimate of the gender bias coefficient $\left(\alpha_{2}\right)$ equals 0.339 in math and 0.080 in literacy, which is very similar to the coefficients obtained by implementing DiD.
} 


\section{VI.B Time Lag between the Date of the Blind and Non-Blind Scores}

The blind and the non-blind scores are not taken exactly at the same date, which can affect my estimates. As mentioned before, the dataset includes a blind and non-blind score from the beginning and end of grade 6 . Yet for both periods, a time lag exists between the date when the national evaluation is taken and the date when the grades are given by teachers. For all regressions presented before, the gender bias is estimated based on scores given at the end of the school year. Pupils take the standardized blind test during one of the last days of the school year, while teachers' assessments are an average of several grades given by teachers between April and mid-June (last term of the academic year). Since the last term lasts three months, this average of several grades measures a pupil's average ability about one and a half months before the end of the school year in mid-June. This time lag between the dates of the blind and non-blind scores might be problematic if girls tend to progress more than boys during this period, especially if girls' better progress is higher in classes where teachers are more biased. Yet, because the blind score is measured after the non-blind score, the doubledifference coefficient, which captures the gender bias, would be a lower bound for the true gender bias if girls tend to progress more. Most importantly, the higher the gender bias of a teacher, the larger the downward bias, so that the time lag would tend to shrink the variance of the gender bias. As a result, my estimates would tend to underestimate the impact of teachers' gender biases on students' progress and subsequent outcomes. ${ }^{28}$

\section{Conclusion}

A number of papers have shown that teachers' stereotypes can bias their assessment and grades, yet none of these papers has gone one step further by studying the impact of teachers' gender biases on students' subsequent progress and schooling trajectories. The main contribution of

\footnotetext{
${ }^{28}$ The direction of the bias would be opposite if the scores collected at the beginning of the year had been used to estimate gender bias. At the beginning of the year, the time lag is reversed: pupils take the standardized blind test during one of the first days of the school year, whereas teachers' assessments are an average of several grades given by teachers during the three first months.
} 
this paper is to answer this question by using a new identification strategy based on the variation of gender biases between teachers and the quasi-random assignment of students to these different teachers. To measure gender biases, I use a standard double-difference methodology that exploits the availability of both blind and non-blind scores for each student.

The key finding is that teachers' gender biases have a high and significant effect on girls' progress relative to boys' in both math and literacy. Over middle school, teachers' gender bias against boys explains 21 percent of boys falling behind girls in math. Although students who are assigned a more biased teacher in grade 6 are more likely to be reassigned the same teacher in grade 7, boys' relative progress is not lower for these students. Moving to other outcomes, I find that having a teacher who is one SD more biased in math increases girls' probability to select a scientific track in high school by 2.7 percentage points compared to boys'. Teachers' average bias in math contributes to a reduction of 11.7 percent of the gender gap in choosing scientific courses.

I use a dataset that has been collected from schools in a relatively deprived educational district in France. This should be kept in mind when interpreting the results and for the external validity of this analysis. Teachers assigned to deprived areas are on average younger than teachers in more advantaged schools, and we have seen that inexperienced teachers are more biased. Similarly, pupils in these areas might face more constraints (financial or self-censorship) regarding their schooling decisions.

An interesting follow-up would be to understand the channels through which a gender bias affects boys' relative achievement. Positively rewarding pupils could provide motivation, lead to increased efforts and self-confidence, and reduce the effects of stereotype threat. On the other hand, if pupils consider effort and abilities as substitutes, a higher grade might be an incentive to reduce effort and work. Unfortunately, I am not able to disentangle these effects, which might compensate or reinforce each other. This is an interesting question for future research. It would also be worthwhile to extend this analysis by using an exhaustive sample of students, ensuring that the sample is large enough to detect small effects. Indeed, one of the drawbacks of my analysis is the limited number of observations available, which makes it more difficult to 
detect an effect.

This analysis provides policy-relevant results. Teachers' gender biases can have a strong impact on the achievement gap between boys and girls. This provides a new explanation for boys increasingly falling behind girls at school and for girls choosing relatively fewer scientific courses in high school. These findings open the door to new policies. If the main objective of policy-makers was to reduce achievement gaps-whether between boys and girls or students from different ethnicities or social backgrounds—teachers' evaluation methods and behavior could be considered as an instrument to achieve that goal.

\section{References}

Angrist Joshua D. Grouped-data estimation and testing in simple labor-supply models // Journal of Econometrics. 1991. 47, 2. 243 - 266.

Angrist Joshua D., Krueger Alan B. Does Compulsory School Attendance Affect Schooling and Earnings? // The Quarterly Journal of Economics. 1991. 106, 4. 979-1014.

Angrist Joshua D, Pischke Jörn-Steffen. Mostly Harmless Econometrics: An Empiricist's Companion. 2008.

Apperson Jarod, Bueno Carycruz, Sass Tim. Do the Cheated Ever Prosper? The Long-run Effects of Test-Score Manipulation by Teachers on Student Outcomes // Working Paper No. 155. 2016.

Ashraf Quamrul, Galor Oded. The 'Out of Africa' Hypothesis, Human Genetic Diversity, and Comparative Economic Development. // American Economic Review. 2013. 103, 1. 1-46.

Autor David, Figlio David, Karbownik Krzysztof, Roth Jeffrey, Wasserman Melanie. School Quality and the Gender Gap in Educational Achievement // SEII Working Paper. 2016. 1.

Avvisati Francesco, Gurgand Marc, Guyon Nina, Maurin Eric. Getting Parents Involved : a Field Experiment in Deprived Schools // Review of Economic Studies. 2014. 81, 1. 57-83.

Azmat Ghazala, Calsamiglia Caterina, Iriberri Nagore. Gender Differences in Response to Big Stakes // Journal of the European Economic Association. 2016.

Bar Talia, Zussman Asaf. Partisan grading // American Economic Journal: Applied Economics. 2012. 4, 1. 30-48.

Bedard Kelly, Dhuey Elizabeth. The Persistence of Early Childhood Maturity: International Evidence of Long-Run Age Effects // The Quarterly Journal of Economics. 2006. 121, 4. $1437-1472$. 
Bertrand Marianne, Pan Jessica. The Trouble with Boys: Social Influences and the Gender Gap in Disruptive Behavior // American Economic Journal: Applied Economics. 2013. 5, 1. 32-64.

Blank Rebecca M. The Effects of Double-Blind versus Single-Blind Reviewing: Experimental Evidence from The American Economic Review // The American Economic Review. 1991. 81, 5. 1041-1067.

Bonesrønning Hans. The Effect of Grading Practices on Gender Differences in Academic Performance // Bulletin of Economic Research. 2008. 60, 3. 245-64.

Breda Thomas, Ly Son Thierry. Professors in Core Science Fields Are Not Always Biased against Women: Evidence from France // American Economic Journal: Applied Economics. 2015. 7, 4. 53-75.

Buckles Kasey S., Hungerman Daniel M. Season of Birth and Later Outcomes: Old Questions, New Answers // Review of Economics and Statistics. 2012. 95, 3. 711-724.

Burgess Simon, Greaves Ellen. Test Scores, Subjective Assessment, and Stereotyping of Ethnic Minorities // Journal of Labor Economics. 2013. 31, 3. 535-576.

Chetty Raj, Friedman John N., Rockoff Jonah E. Measuring the Impacts of Teachers I: Evaluating Bias in Teacher Value-Added Estimates. // American Economic Review. 2014. 104, 9. 2593-2632.

Cornwell Christopher, Mustard David B., Parys Jessica Van. Noncognitive Skills and the Gender Disparities in Test Scores and Teacher Assessments: Evidence from Primary School // Journal of Human Resources. 2013. 48, 1. 236-264.

Crawford Claire, Dearden Lorraine, Meghir Costas. When You Are Born Matters: The Impact of Date of Birth on Child Cognitive Outcomes in England // CEE Discusion Paper. 2007.

Cunha Flavio, Heckman James J. Formulating, Identifying and Estimating the Technology of Cognitive and Noncognitive Skill Formation // Journal of Human Resources. 2008. 43, 4. 738-782.

Dee Thomas, Dobbie Will, Jacob Brian, Rockoff Jonah. The Causes and Consequences of Test Score Manipulation: Evidence from the New York Regents Examinations // NBER Working Paper No. 22165. 2016.

Dee Thomas S. A Teacher Like Me: Does Race, Ethnicity, or Gender Matter? // American Economic Review. 2005. 95, 2. 158-165.

Dee Thomas S. Teachers and the Gender Gaps in Student Achievement // The Journal of Human Resources. 2007. 42, 3. 528-554.

Diamond Rebecca, Persson Petra. The Long-term Consequences of Teacher Discretion in Grading of High-stakes Tests // NBER Working Paper No. 22207. 2016.

Falch Torberg, Naper Linn Renée. Educational Evaluation Schemes and Gender Gaps in Student Achievement // Economics of Education Review. 2013. 36. 12-25. 
Fennema Elizabeth, Peterson Penelope L., Carpenter Thomas P., Lubinski Cheryl A. Teachers' Attributions and Beliefs about Girls, Boys, and Mathematics // Educational Studies in Mathematics. 1990. 21, 1. 55-69.

French Ministry of Education . Les pratiques d'évaluation des enseignants en collège // Dossier 160. 2005.

Gneezy Uri, Niederle Muriel, Rustichini Aldo. Performance in Competitive Environments: Gender Differences // The Quarterly Journal of Economics. 2003. 118, 3. 1049-1074.

Goldin Claudia, Rouse Cecilia. Orchestrating Impartiality: The Impact of "Blind" Auditions on Female Musicians // American Economic Review. 2000. 90, 4. 715-741.

Hanna Rema N., Linden Leigh L. Discrimination in Grading // American Economic Journal: Economic Policy. 2012. 4, 4. 146-68.

Heckman James J., Rubinstein Yona. The Importance of Noncognitive Skills: Lessons from the GED Testing Program // American Economic Review. 2001. 91. 145-149.

Hinnerich Björn Tyrefors, Höglin Erik, Johannesson Magnus. Are boys discriminated in Swedish high schools? // Economics of Education Review. 2011. 30, 4. 682-690.

Hoff Karla, Pandey Priyanka. Discrimination, Social Identity, and Durable Inequalities // The American Economic Review. 2006. 96, 2. 206-211.

Jacob Brian A., Lefgren Lars. Principals as Agents: Subjective Performance Measurement in Education // NBER Working Paper. 2005. 11463.

Jussim L., Eccles J. Teachers Expectations II: Contruction and Reflection of Student Achievement // Journal of Personality and Social Psychology. 1992. 63. 947-961.

Kane Thomas J., Staiger Douglas $O$. The Promise and Pitfalls of Using Imprecise School Accountability Measures. // Journal of Economic Perspectives. 2002. 16, 4. 91-114.

Estimating Teacher Impacts on Student Achievement: An Experimental Evaluation. // . 2008.

Lavy Victor. Do gender stereotypes reduce girls' or boys' human capital outcomes? Evidence from a natural experiment // Journal of Public Economics. 2008. 92, 10. 2083-2105.

Lavy Victor, Sand Edith. On The Origins of Gender Human Capital Gaps: Short and Long Term Consequences of Teachers' Stereotypical Biases // NBER Working Paper. 2015. 20909.

Legewie Joscha, DiPrete Thomas A. School Context and the Gender Gap in Educational Achievement. // American Sociological Review. 2012. 77, 3.

Lindahl Erica. Does gender and ethnic background matter when teachers set school grades? Evidence from Sweden // Uppsala University. 2007. Working paper.

Machin Stephen, McNally Sandra. Gender and Student Achievement in English Schools // Oxford Review of Economic Policy. 2005. 21, 3. 357-372. 
Marsh Herbert. W., Craven Rhonda G. Academic self-concept: Beyond the dustbowl. // In G. D. Phye (Ed.), Handbook of classroom assessment. San Diego, CA: Academic Press. 1997. 131:198.

Mechtenberg Lydia. Cheap Talk in the Classroom: How Biased Grading at School Explains Gender Differences in Achievements, Career Choices and Wages // Review of Economic Studies. 2009. 76, 4. 1431-1459.

Murphy Kevin M., Topel. Robert H. Estimation and Inference in Two-Step Econometric Models. // Journal of Business and Economic Statistics. 1985. 3, 4. 370-79.

Murphy Richard, Weinhardt Felix. The Importance of Rank Position // CEP Discussion Paper. 2013.

OECD . Education Indicators In Focus // OECD Publishing. 2012.

$O E C D$. The ABC of Gender Equality in Education: Aptitude, Behaviour, Confidence // OECD Publishing. 2015.

Ouazad Amine, Page Lionel. Students' perceptions of teacher biases: Experimental economics in schools // Journal of Public Economics. 2013. 105. 116-130.

Pagan Adrian. Econometric Issues in the Analysis of Regressions with Generated Regressors. // Inter Economic Review. 1984. 25, 1. 221-47.

Robinson Joseph Paul, Lubienski Sarah Theule. The Development of Gender Achievement Gaps in Mathematics and Reading During Elementary and Middle School Examining Direct Cognitive Assessments and Teacher Ratings // American Educational Research Journal. 2011. 48, 2. 268-302.

Spencer Steven J., Steele Claude M., Quinn Diane M. Stereotype Threat and Women's Math Performance // Journal of Experimental Social Psychology. 1999. 35, 1. 4-28.

Steele Claude M., Aronson Joshua. Stereotype threat and the intellectual test performance of African Americans // Journal of Personality and Social Psychology. 1995. 69, 5. 797-811.

Tiedemann Joachim. Gender related beliefs of teachers in elementary school mathematics // Educational Studies in Mathematics. 2000. 41. 191-207.

Trautwein Ulrich, Ludtke Oliver, Marsh Herbert W., Koller Olaf, Baumert Jurgen. Tracking, Grading, and Student Motivation: Using Group Composition and Status to Predict SelfConcept and Interest in Ninth-Grade Mathematics // Journal of Educational Psychology. 2006. 98, 4. 788-806. 
Table 1: DESCRIPTIVE STATISTICS FOR BOYS AND GIRLS

\begin{tabular}{lccccc}
\hline \hline & All & Boys & Girls & & \\
\cline { 2 - 6 } & $\begin{array}{c}\text { Mean } \\
(1)\end{array}$ & $\begin{array}{c}\text { Mean } \\
(2)\end{array}$ & $\begin{array}{c}\text { Mean } \\
(3)\end{array}$ & $\begin{array}{c}\text { Difference } \\
(4)=(3)-(2)\end{array}$ & p-value \\
Variables & & & & & \\
\hline & & & & & \\
Pupils' test scores in grade 6 & -0.000 & -0.211 & 0.223 & $0.434^{* * *}$ & $(0.000)$ \\
Blind - Literacy & 0.000 & 0.072 & -0.075 & $-0.147^{* * *}$ & $(0.000)$ \\
Blind - Math & 0.000 & -0.224 & 0.236 & $0.460^{* * *}$ & $(0.000)$ \\
Non-Blind - Literacy & -0.000 & -0.083 & 0.087 & $0.170^{* * *}$ & $(0.000)$ \\
Non-Blind - Math & & & & & \\
& & & & & \\
Pupils' characteristics in grade 6 & 0.062 & 0.074 & 0.049 & $-0.026^{* * * *}$ & $(0.000)$ \\
\% Grade repetition & 0.062 & 0.097 & 0.025 & $-0.072^{* * * *}$ & $(0.000)$ \\
\% Disciplinary warning & 0.056 & 0.086 & 0.023 & $-0.064^{* * *}$ & $(0.000)$ \\
\% Excluded from class & 0.036 & 0.062 & 0.008 & $-0.054^{* * *}$ & $(0.000)$ \\
\% Temporary exclusion from school & & & & & \\
& & & & & \\
Parents' characteristics in grade 6 & & & & \\
\% High SES & 0.178 & 0.185 & 0.170 & $-0.015^{* * * *}$ & $(0.000)$ \\
\% Low SES & 0.686 & 0.672 & 0.701 & $0.028^{* * *}$ & $(0.000)$ \\
\% Unemployed & 0.117 & 0.120 & 0.114 & $-0.006^{* * * *}$ & $(0.000)$ \\
& & & & & \\
Teachers' characteristics in grade 6 & & & & & \\
\% Female teachers - Math & & & & & \\
\% Female teachers - Literacy & 0.499 & 0.504 & 0.494 & $-0.011^{* * * *}$ & $(0.000)$ \\
Teachers' age - Math & 0.846 & 0.846 & 0.845 & $-0.001^{* * * *}$ & $(0.000)$ \\
Teachers' age - Literacy & 34.378 & 34.354 & 34.403 & 0.049 & $(0.599)$ \\
Schools and courses attended after grade 10 & & & & & \\
\% General high school (grade 10) & 0.457 & 0.403 & 0.509 & $0.106^{* * *}$ & $(0.000)$ \\
\% Scientific track (grade 11) & 0.165 & 0.162 & 0.167 & $0.005^{* * *}$ & $(0.000)$ \\
\% Literature track (grade 11) & 0.063 & 0.030 & 0.095 & $0.065^{* * *}$ & $(0.000)$ \\
& & & & & \\
\hline Number of observations & 4490 & 2332 & 2158 & & \\
\hline \hline
\end{tabular}

${ }^{\dagger}$ Notes: Stars correspond to the following p-values: $* \mathrm{p}<.05 ; * * \mathrm{p}<.01 ; * * * \mathrm{p}<.001$. This table presents differences between boys' and girls' characteristics. Column 4 reports the coefficients of the regression of various dependent variables on a dummy indicating that the pupil is a girl. All scores are standardized. Standard errors are robust.

Parents' professions: Parents belong to the high SES category if they belong to the French administrative category "corporate manager" or "executive." Parents are classified as low SES if they belong to the categories "worker" or "white-collar worker." For both variables, the dummy takes the value 1 if at least one of the parents belongs to the category. 
Distribution of Blind AND Non-Blind scores (GRAde 6) - LiteraCY

Figure 1: BLIND SCORE

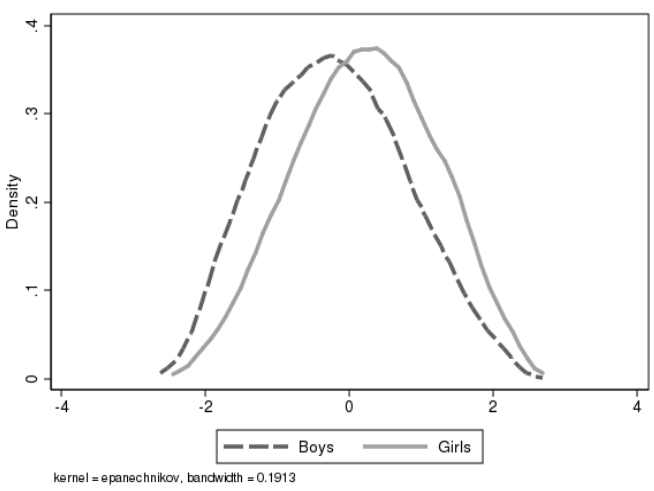

Figure 2: NON-BLIND SCORE

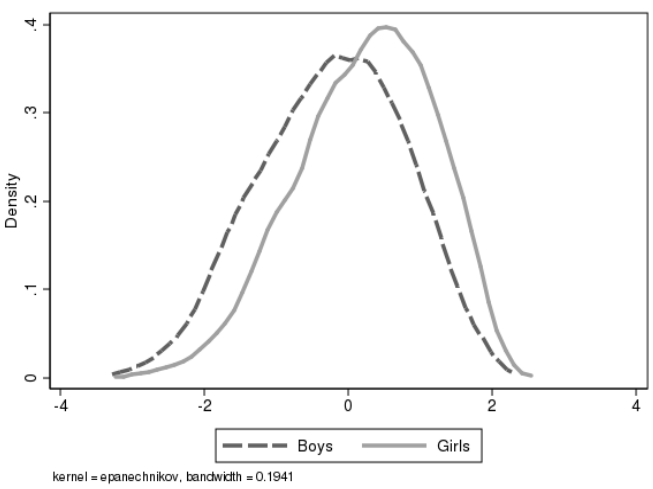

Distribution of Blind And Non-Blind scores (GRAde 6) - MATH

Figure 3: BLIND SCORE

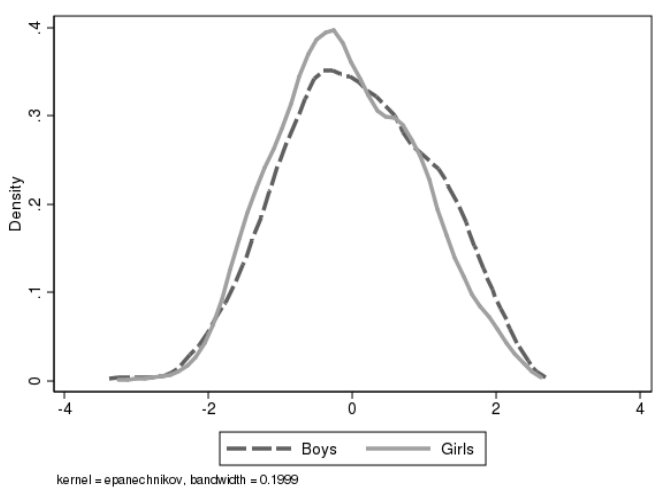

Figure 4: NON-BLIND SCORE

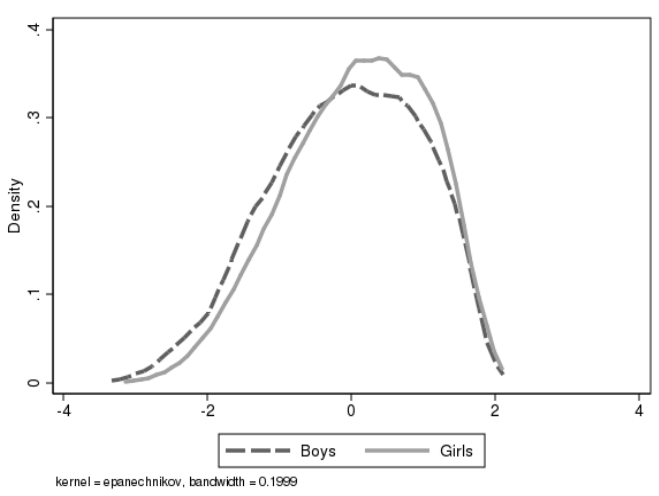


BOYS AND GIRLS' PROGRESS OVER MIDDLE SCHOOL

Figure 5: LITERACY

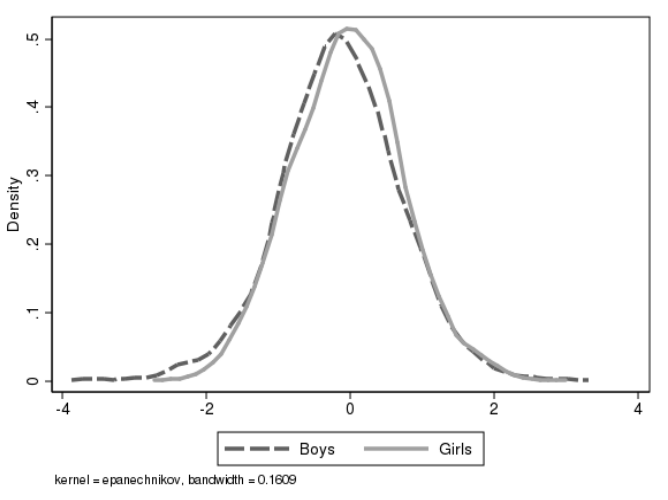

Figure 6: MATH

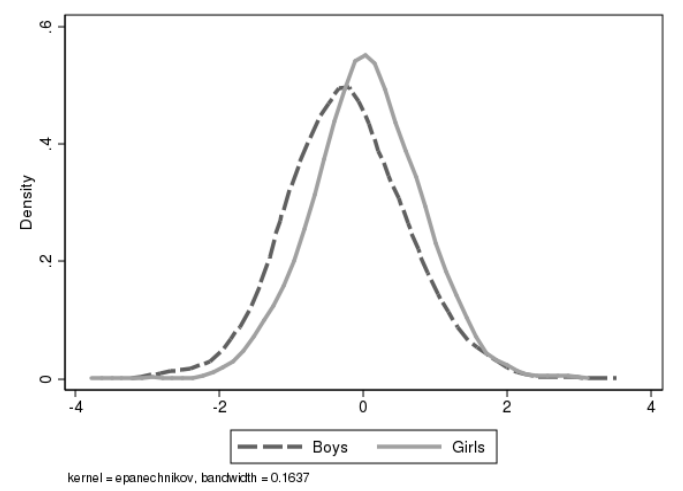

CORRELATION BETWEEN TEACHERS' GENDER BIASES AND GIRLS' RELATIVE PROGRESS OVER MIDDLE SCHOOL

Figure 7: LITERACY

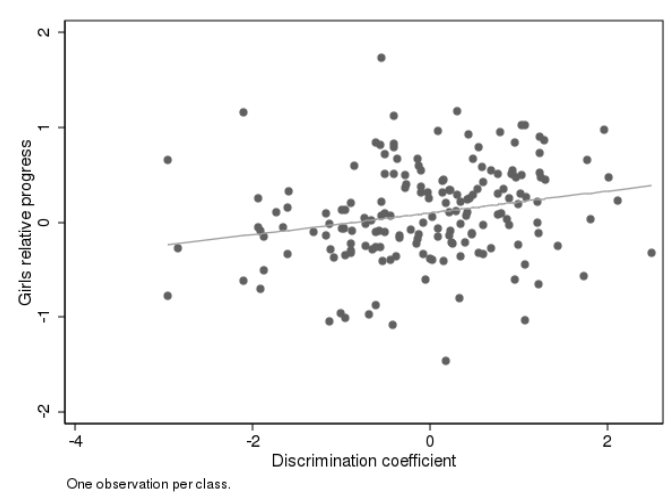

Figure 8: MATH

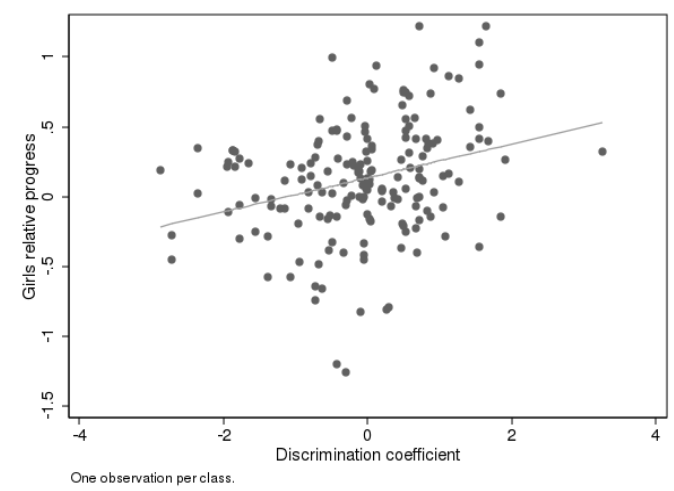


Table 2: ESTIMATION OF THE GENDER BIAS

\begin{tabular}{|c|c|c|c|c|c|}
\hline Dep var : Math scores & $(1)$ & (2) & (3) & (4) & $(5)$ \\
\hline Girl x Non-Blind & $\begin{array}{c}0.318^{* * * *} \\
(0.027)\end{array}$ & $\begin{array}{c}0.327 * * * \\
(0.031)\end{array}$ & $\begin{array}{c}0.317 * * * \\
(0.029)\end{array}$ & $\begin{array}{c}0.313 * * * \\
(0.027)\end{array}$ & $\begin{array}{c}0.318 * * * \\
(0.031)\end{array}$ \\
\hline Girl & $\begin{array}{c}-0.152 * * * \\
(0.028)\end{array}$ & $\begin{array}{c}-0.146^{* *} \\
(0.040)\end{array}$ & $\begin{array}{c}-0.211^{* * *} \\
(0.039)\end{array}$ & $\begin{array}{c}-0.160 * * * \\
(0.028)\end{array}$ & $\begin{array}{c}-0.221 * * * \\
(0.039)\end{array}$ \\
\hline Non-Blind Score & $\begin{array}{c}-0.156^{* *} \\
(0.052)\end{array}$ & $\begin{array}{c}-0.170 * \\
(0.064)\end{array}$ & $\begin{array}{c}-0.147 * \\
(0.067)\end{array}$ & $\begin{array}{c}-0.150 * * \\
(0.051)\end{array}$ & $\begin{array}{l}-0.145 \\
(0.071)\end{array}$ \\
\hline Controls for punishment & & & . & & . \\
\hline Punishment & & & $\begin{array}{c}-0.566 * * * \\
(0.076)\end{array}$ & & $\begin{array}{c}-0.546^{* * *} * \\
(0.075)\end{array}$ \\
\hline Punishment $\mathrm{x}$ Non-Blind & & & $\begin{array}{c}-0.153 * \\
(0.071)\end{array}$ & & $\begin{array}{c}-0.152 * \\
(0.070)\end{array}$ \\
\hline Punishment $\mathrm{x}$ Non-Blind $\mathrm{x}$ Girl & & & $\begin{array}{l}-0.301 \\
(0.157)\end{array}$ & & $\begin{array}{l}-0.296 \\
(0.170)\end{array}$ \\
\hline Controls for grade repetition & & & & . & . \\
\hline Grade repetition & & & & $\begin{array}{c}-0.352 * * * \\
(0.090)\end{array}$ & $\begin{array}{c}-0.383^{* *} \\
(0.125)\end{array}$ \\
\hline Repetition $\mathrm{x}$ Non-Blind & & & & $\begin{array}{c}-0.076 \\
(0.133)\end{array}$ & $\begin{array}{l}-0.007 \\
(0.096)\end{array}$ \\
\hline Repetition $\mathrm{x}$ Non-Blind $\mathrm{x}$ Girl & & & & $\begin{array}{c}0.077 \\
(0.112)\end{array}$ & $\begin{array}{l}-0.040 \\
(0.165)\end{array}$ \\
\hline Constant & $\begin{array}{c}2.361 * * * \\
(0.133)\end{array}$ & $\begin{array}{c}4.717 * * * \\
(0.062)\end{array}$ & $\begin{array}{c}5.034 * * * \\
(0.067)\end{array}$ & $\begin{array}{c}2.492 * * * \\
(0.127)\end{array}$ & $\begin{array}{c}5.170 * * * \\
(0.072)\end{array}$ \\
\hline Class FE & Yes & Yes & Yes & Yes & Yes \\
\hline R2 & 0.118 & 0.105 & 0.136 & 0.125 & 0.143 \\
\hline Number of observations & 8329 & 4413 & 4413 & 8329 & 4413 \\
\hline
\end{tabular}

Notes: The dependent variable is the score (both blind and non-blind) obtained by a pupil in math during the first term of grade 6. Each pupil has two observations: one for the blind score and one for the non-blind score. The sample used in columns 2, 3, and 5 does not include pupils for which a punishment variable is missing. Standard errors are in parentheses and have been estimated with school-level clusters. Stars correspond to the following $\mathrm{p}$-values: $* \mathrm{p}<.05$; $* *$ $\mathrm{p}<.01 ; * * * \mathrm{p}<.001$. 
Table 3: INDEPENDANCE OF TEACHERS'

ASSIGNMENT

\begin{tabular}{lcccc}
\hline \hline \multirow{2}{*}{ Dep var: Bias } & \multicolumn{2}{c}{ Math } & \multicolumn{2}{c}{ Literacy } \\
\cline { 2 - 5 } Blind & Girls & Boys & Girls & Boys \\
& -0.003 & $-0.052^{* *}$ & 0.019 & -0.029 \\
& $(0.020)$ & $(0.018)$ & $(0.021)$ & $(0.020)$ \\
High SES & 0.044 & -0.039 & $-0.154^{* *}$ & 0.004 \\
& $(0.046)$ & $(0.047)$ & $(0.051)$ & $(0.046)$ \\
Low SES & -0.031 & 0.038 & 0.075 & 0.061 \\
& $(0.038)$ & $(0.038)$ & $(0.042)$ & $(0.039)$ \\
Grade repetition & -0.092 & 0.121 & $-0.196^{* *}$ & -0.044 \\
& $(0.071)$ & $(0.065)$ & $(0.090)$ & $(0.071)$
\end{tabular}

$\dagger$ Notes: Stars correspond to the following p-values: $* \mathrm{p}<.05 ; * *$ $\mathrm{p}<.01 ; * * * \mathrm{p}<.001$. Each cell in this table corresponds to the coefficient of a separate regression run on the full sample. For instance, the upper left cell reports the coefficient of the regression of the bias of math teachers on the blind score of girls in math.

Table 4:

BALANCE CHECK OF ATTRITION AT THE INDIVIDUAL LEVEL

\begin{tabular}{lcccccccc}
\hline \hline & \multicolumn{2}{c}{ Grade 9 } & & \multicolumn{2}{c}{ Grade 10 } & & \multicolumn{2}{c}{ Grade 11 } \\
\cline { 2 - 3 } \cline { 8 - 9 } \cline { 8 - 9 } & Math & Literacy & & Math & Literacy & & Math & Literacy \\
\hline Dep var: \% girls missing & 0.005 & -0.004 & & -0.002 & -0.001 & & -0.002 & -0.001 \\
& $(0.011)$ & $(0.009)$ & & $(0.011)$ & $(0.009)$ & & $(0.011)$ & $(0.009)$ \\
\hline Dep var: \% boys missing & 0.001 & -0.003 & & 0.001 & -0.008 & & 0.001 & -0.008 \\
& $(0.010)$ & $(0.009)$ & & $(0.009)$ & $(0.010)$ & & $(0.009)$ & $(0.010)$ \\
\hline Number of observations & 177 & 172 & & 177 & 172 & & 177 & 172 \\
\hline \hline
\end{tabular}

$\dagger$ Notes: Stars correspond to the following $\mathrm{p}$-values: $* \mathrm{p}<.05 ; * * \mathrm{p}<.01 ; * * * \mathrm{p}<.001$. One observation per class. In the upper and bottom part of the table, the dependent variable corresponds to the percentage of girls (respectively boys) with a missing score. In columns 1 and 2, the dependent variable is the percentage of girls (respectively boys) for which the blind score is missing at the end of grade 9 (blind score missing in math in column 1 and literature in column 2). In columns 3 and 4, the dependent variable is the percentage of girls (respectively boys) for which the high school attended from grade 10 is missing. In columns 5 and 6 , the dependent variable is the percentage of girls (respectively boys) for which the course choice in grade 11 is missing. Robust standard errors. 
Table 5: EFFECT OF TEACHERS' GENDER BIASES ON GIRLS' PROGRESS RELATIVE TO BOYS

\begin{tabular}{lcc}
\hline \hline & Math & Literature \\
Dep var : $\left(\text { Progres }_{G}-\text { Progres }_{B}\right)_{c}$ & & \\
\hline & & \\
Gender bias & $0.136^{* * *}$ & $0.129^{* *}$ \\
& $(0.047)$ & $(0.053)$ \\
Achievement gap & $-0.191^{* * *}$ & $-0.178^{* *}$ \\
& $(0.069)$ & $(0.090)$ \\
Constant & $0.088^{* * * *}$ & $0.160^{* * *}$ \\
& $(0.032)$ & $(0.046)$ \\
\hline Observations & 177 & 172 \\
R-Square & 0.132 & 0.079 \\
\hline \hline
\end{tabular}

$\dagger$ Notes: The unit of observation is a class. The dependent variable is the gap between girls' and boys' progress between the beginning of grade 7 and the end of grade 9. Standard errors are in parentheses and have been estimated with a two-step bootstrapping method. Stars correspond to the following $\mathrm{p}$-values: $* \mathrm{p}<.10$; ** $\mathrm{p}<.05$; *** $\mathrm{p}<.01$.

Table 6: EFFECT OF TEACHERS' GENDER BIASES ON GIRLS' SCHOOL CHOICE, COURSE CHOICE, AND GRADE REPETITION RELATIVE TO BOYS'

\begin{tabular}{|c|c|c|c|c|c|c|c|c|}
\hline \multirow[t]{3}{*}{$\begin{array}{l}\text { Dep var: } \\
\left(\operatorname{Prob}_{G}-\operatorname{Prob}_{B}\right)_{c}\end{array}$} & \multicolumn{2}{|c|}{ General HS } & \multicolumn{2}{|c|}{ Science } & \multicolumn{2}{|c|}{ Literature } & \multicolumn{2}{|c|}{ Repetition } \\
\hline & \multicolumn{2}{|c|}{ Bias in } & \multicolumn{2}{|c|}{ Bias in } & \multicolumn{2}{|c|}{ Bias in } & \multicolumn{2}{|c|}{ Bias in } \\
\hline & Math & Literacy & Math & Literacy & Math & Literacy & Math & Literacy \\
\hline Gender bias & $\begin{array}{c}0.015 \\
(0.021)\end{array}$ & $\begin{array}{c}0.007 \\
(0.022)\end{array}$ & $\begin{array}{l}0.027 * \\
(0.016)\end{array}$ & $\begin{array}{c}0.013 \\
(0.015)\end{array}$ & $\begin{array}{l}-0.009 \\
(0.010)\end{array}$ & $\begin{array}{c}0.005 \\
(0.011)\end{array}$ & $\begin{array}{l}-0.026 \\
(0.019)\end{array}$ & $\begin{array}{l}-0.014 \\
(0.021)\end{array}$ \\
\hline Achievement gap & $\begin{array}{l}0.208 * * * \\
(0.034)\end{array}$ & $\begin{array}{l}0.263 * * * \\
(0.034)\end{array}$ & $\begin{array}{l}0.149 * * * \\
(0.024)\end{array}$ & $\begin{array}{l}0.152 * * * \\
(0.025)\end{array}$ & $\begin{array}{c}0.047 * * \\
(0.019)\end{array}$ & $\begin{array}{c}0.047 * * \\
(0.019)\end{array}$ & $\begin{array}{c}-0.072 * * \\
(0.029)\end{array}$ & $\begin{array}{c}-0.077 * * \\
(0.036)\end{array}$ \\
\hline Constant & $\begin{array}{c}0.125^{* * *} * \\
(0.017)\end{array}$ & $\begin{array}{l}-0.017 \\
(0.021)\end{array}$ & $\begin{array}{l}0.022 * \\
(0.012)\end{array}$ & $\begin{array}{l}0.023 * \\
(0.013)\end{array}$ & $\begin{array}{c}0.048 * * * \\
(0.012)\end{array}$ & $\begin{array}{c}0.049 * * * \\
(0.011)\end{array}$ & $\begin{array}{c}-0.108 * * * \\
(0.015)\end{array}$ & $\begin{array}{c}-0.063 * * * \\
(0.019)\end{array}$ \\
\hline Observations & 177 & 172 & 177 & 172 & 177 & 172 & 177 & 172 \\
\hline R-Square & 0.158 & 0.184 & 0.173 & 0.149 & 0.031 & 0.031 & 0.047 & 0.031 \\
\hline $\begin{array}{l}\dagger \text { Notes: The unit of } \\
\text { probability to cho } \\
\text { girls' and boys' pr } \\
\text { between girls' and } \\
\text { the gap between g }\end{array}$ & $\begin{array}{l}\text { servation } \\
\text { a general } \\
\text { bility to c } \\
\text { ys' probal } \\
\text { and boys }\end{array}$ & $\begin{array}{l}\text { a class. I } \\
\text { gh school } \\
\text { ose a sci } \\
\text { ity to cho } \\
\text { robabilit }\end{array}$ & $\begin{array}{l}\text { lumns } 1 \text { a } \\
\text { m grade } 1 \\
\text { fic track ir } \\
\text { a literatur } \\
\text { repeat a } \mathrm{g}\end{array}$ & $\begin{array}{l}\mathrm{d} 2 \text {, the } \mathrm{d} \\
\text { In colum } \\
\text { rade } 11 . \\
\text { rack in } \mathrm{g} \\
\text { de. Stand }\end{array}$ & $\begin{array}{l}\text { Adent var } \\
3 \text { and } 4, \mathrm{t} \\
\text { olumns } 5 \\
11 . \text { In ce }\end{array}$ & $\begin{array}{l}\text { le is the } \\
\text { dependen } \\
\text { dd } 6 \text {, the } \\
\text { mns } 7 \text { an }\end{array}$ & $\begin{array}{l}\text { between gi } \\
\text { riable is th } \\
\text { endent vari } \\
\text { the depend }\end{array}$ & $\begin{array}{l}\text { ls' and boys } \\
\text { gap betweer } \\
\text { ole is the gap } \\
\text { nt variable is }\end{array}$ \\
\hline
\end{tabular}


Table 7: EFFECT OF TEACHERS' BIASES WITH SPILLOVERS

\begin{tabular}{|c|c|c|c|c|c|c|}
\hline \multirow{2}{*}{$\begin{array}{l}\text { Dep var: } \\
\left(P_{G}-P_{B}\right)_{c}\end{array}$} & \multicolumn{4}{|c|}{$\begin{array}{c}\text { Progress over } 3 \text { years } \\
\text { in }\end{array}$} & \multicolumn{2}{|c|}{$\begin{array}{l}\text { Science } \\
\text { course }\end{array}$} \\
\hline & Math & Math & Literature & Literature & & \\
\hline Gender Bias Math & $\begin{array}{c}0.136^{* * * *} \\
(0.047)\end{array}$ & $\begin{array}{c}0.135^{* * *} \\
(0.047)\end{array}$ & & $\begin{array}{c}0.067 \\
(0.057)\end{array}$ & $\begin{array}{l}0.026^{*} \\
(0.015)\end{array}$ & $\begin{array}{l}0.025 \\
(0.016)\end{array}$ \\
\hline Gender Bias Literacy & & $\begin{array}{c}0.034 \\
(0.038)\end{array}$ & $\begin{array}{l}0.129 * * \\
(0.053)\end{array}$ & $\begin{array}{c}0.134 * * * \\
(0.046)\end{array}$ & & $\begin{array}{c}0.009 \\
(0.015)\end{array}$ \\
\hline Achievement Gap & $\begin{array}{c}-0.191 * * * \\
(0.069)\end{array}$ & $\begin{array}{c}-0.209 * * * \\
(0.071)\end{array}$ & $\begin{array}{c}-0.178 * * \\
(0.090)\end{array}$ & $\begin{array}{c}-0.197 * * \\
(0.089)\end{array}$ & $\begin{array}{c}0.151 * * * \\
(0.022)\end{array}$ & $\begin{array}{c}0.148 * * * \\
(0.023)\end{array}$ \\
\hline Constant & $\begin{array}{c}0.088^{* * *} \\
(0.032)\end{array}$ & $\begin{array}{l}0.080 * * \\
(0.032)\end{array}$ & $\begin{array}{c}0.160 * * * \\
(0.046)\end{array}$ & $\begin{array}{c}0.177 * * * \\
(0.045)\end{array}$ & $\begin{array}{c}0.026^{* *} \\
(0.012)\end{array}$ & $\begin{array}{c}0.028 * * \\
(0.012)\end{array}$ \\
\hline Observations & 177 & 170 & 172 & 170 & 177 & 170 \\
\hline R-Square & 0.132 & 0.154 & 0.079 & 0.108 & 0.190 & 0.184 \\
\hline
\end{tabular}

${ }^{\dagger}$ Notes: The unit of observation is a class. In columns 1 to 4 , the dependent variable is the gap between girls' and boys' progress between the beginning of grade 7 and the end of grade 9 . In columns 5 and 6 , the dependent variable is the gap between girls' and boys' probability to select a science course in grade 11. Standard errors are in parentheses and have been estimated with a two-step bootstrapping method. Stars correspond to the following p-values: $* \mathrm{p}<.10 ; * * \mathrm{p}<.05 ; * * * \mathrm{p}<.01$.

Table 8: CUMUlative EFFECT OF TEACHERS’ BIASES

\begin{tabular}{lcccc}
\hline \hline $\begin{array}{l}\text { Dep var: } \\
\left(\text { Progres }_{G}-\text { Progres }_{B}\right)_{c}\end{array}$ & Math & Math & Literature & Literature \\
\hline & & & & \\
Gender Bias & $0.136^{* * * *}$ & $0.142^{* * * *}$ & $0.129^{* *}$ & $0.118^{*}$ \\
& $(0.047)$ & $(0.051)$ & $(0.053)$ & $(0.064)$ \\
Achievement Gap & $-0.191^{* * *}$ & $-0.191^{* * *}$ & $-0.178^{* *}$ & $-0.178^{* *}$ \\
& $(0.069)$ & $(0.070)$ & $(0.090)$ & $(0.090)$ \\
Gender Bias*Pct Same Teacher & & -0.075 & & 0.112 \\
& & $(0.270)$ & & $(0.298)$ \\
\hline Observations & 177 & 177 & 172 & 172 \\
R-Square & 0.132 & 0.133 & 0.079 & 0.081 \\
\hline \hline
\end{tabular}

$\dagger$ Notes: The unit of observation is a class. In columns 1 to 4 , the dependent variable is the gap between girls' and boys' progress between the beginning of grade 7 and the end of grade 9. Standard errors are in parentheses and have been estimated with a two-step bootstrapping method. Stars correspond to the following $\mathrm{p}$-values: ${ }^{*} \mathrm{p}<.10 ; * * \mathrm{p}<.05 ; * * *$ $\mathrm{p}<.01$. 
BOYS LAG BEHIND.

HOW TEACHERS' GENDER BIASES AFFECT STUDENTS' ACHIEVEMENT

Camille Terrier

APPENDIX

\section{A Additional tables}




\begin{tabular}{|c|c|}
\hline Blind score & Non-Blind score \\
\hline \multicolumn{2}{|l|}{ Math } \\
\hline Space and geometry & Geometry \\
\hline Recognize and draw two-dimensional figures & Two-dimensional figures \\
\hline Properties of alignment, perpendicular, parallel, and symmetry & Symmetry of a straight line \\
\hline Recognize a cube shape and parallelepiped rectangle & Parallelepiped rectangle \\
\hline How to exploit numerical data & Organize and understand data \\
\hline Solve a problem using proportionality & Proportionality \\
\hline Solve problems with addition/substraction/multiplication/division & Read information in tables \\
\hline Read and interpret a table, diagram, and graphic & Read information on axis, diagrams/graphics \\
\hline Size and measurement & Size and measurement \\
\hline Knowledge and use of measurement units & Length, mass, and duration \\
\hline (length, mass, volums, and duration) & Angles \\
\hline & Area: measure, comparison, and calculus \\
\hline & Volumes \\
\hline Knowledge of natural whole numbers & Numbers and calculus \\
\hline Knowledge of integers & Integer numbers and decimals \\
\hline Use and writing of fractions & Fractions \\
\hline \multicolumn{2}{|l|}{ Use decimal numbers } \\
\hline \multicolumn{2}{|l|}{ Calculus } \\
\hline Knowledge of the four operations & Operations \\
\hline \multicolumn{2}{|l|}{ Literacy } \\
\hline Knowledge and recognition of words & Grammar \\
\hline Understand the formation of words & Classes of words (noun, pronoun, verb) \\
\hline Exploit time-space indications & Conjugation \\
\hline \multirow[t]{4}{*}{ Knowledge of verb tenses } & Tenses (present/past/future) \\
\hline & Spelling \\
\hline & Grammatical spelling \\
\hline & Lexical spelling \\
\hline Understanding of words & Vocabulary \\
\hline Decipher rare words & Reading \\
\hline \multirow{2}{*}{\multicolumn{2}{|c|}{$\begin{array}{l}\text { Understand the meaning of a word with its context } \\
\text { Classify and link information }\end{array}$}} \\
\hline & \\
\hline Production of a text & Writing \\
\hline Add punctuation to a text & Use of punctuation \\
\hline Produce a coherent text & Production of a text (one page max) \\
\hline \multicolumn{2}{|l|}{ Transform a text } \\
\hline \multicolumn{2}{|l|}{ Use of usual words } \\
\hline & $\begin{array}{l}\text { Oral expression (reading aloud, recitation) } \\
\text { Initiation to art history }\end{array}$ \\
\hline
\end{tabular}




\section{B Estimation of Teachers' Gender Bias with Control Vari-}

\section{ables}

In this section, I successively check how pupils' disruptive behavior in the class, having repeated a grade, and pupils' initial achievement affect the gender bias estimate. Taking this into account is important, as these variables could be correlated to both teachers' gender bias and a student's progress.

Controlling for Pupils' Disruptive Behavior and Grade Repetition. Boys are more disruptive than girls (Table 1). If bad behavior influences teachers' assessments (consciously or not), this could affect the estimate of the gender bias. ${ }^{29}$ Based on the extensive information I have on pupils' behavior, I create a variable "punishment" that takes a value of 1 if a pupil has received a disciplinary warning from the class council during the first term of grade 6 or if he/she was temporarily excluded from the school. It is important to highlight that both punishments are not given by a single teacher, but by the head teacher in agreement with all the teachers of a student. From that perspective, punishment is not determined solely by the teachers handing out grades. During the first term of grade 6,8 percent of pupils- 85 percent of which were boys-received at least one sanction. ${ }^{30}$ Results including the punishment variable are presented in Table 2, column 3. ${ }^{31}$ Regressions are run in math only, where a gender bias is observed. Column 2 presents results of the standard DiD regression implemented on the smaller sample of students for which the punishment information is available. The coefficient

\footnotetext{
${ }^{29}$ Cornwell et al. (2013), using data from the 1998-1999 ECLS-K cohort of primary school pupils, took into account pupils' non cognitive skills to explain why "boys who perform equally as well as girls on reading, math and science tests are graded less favorably by their teachers." More specifically, the authors used teachers' reported information on how well a pupil is "engaged in the classroom" and found that controlling for this variable significantly reduces or completely removes the bias in teachers' grades, depending on pupils' ethnicity and the grade considered.

${ }^{30}$ This gender gap in disruptive behavior is consistent with prior research. In the U.S., by fifth grade, Bertrand, Pan (2013) found that girls score about half a standard deviation below boys in teacher-reported externalizing problems, which is an important determinant of school suspension.

${ }^{31}$ Several schools did not provide information on their pupils' behavior, so that the punishment variable is missing for some pupils. Therefore, following regressions will focus on the sample of 2269 pupils for which punishments are available. Because this sample is different from the full sample, I run a balance check to verify if pupils' characteristics differ. No significant differences are found regarding the blind score, non-blind score, gender, and parents' professions. Even if schools that do not provide information on sanctions are the ones with the worst-behaved students, my results will be a lower bound of the effect of pupils' behavior on gender bias.
} 
for teachers' gender biases decreases when I control for pupils' behavior, but the drop is very small: the point estimate goes from 0.327 to 0.317 . This suggests that the gender bias I observe in math does not capture boys' disruptive behavior. ${ }^{32}$

Grade repetition is another characteristic that might influence teachers' grades. Like behavior, grade repetition is not equally distributed for boys and girls. Among pupils who have repeated a grade, 62.2 percent are boys. As previously, I include a dummy for grade repetition in the regression. Results presented in column 4 of Table 2 suggest that grade repetition does not explain the bias against boys. I also test whether parents' professions have an impact on teachers' gender biases and find no significant effect of pupils' social backgrounds.

Quantile Regressions. Finally, I test if the bias against boys captures two potentially related effects: (1) some teachers might give more favorable grades to low achievers, and (2) in some classes, the variance of teachers' grades might be smaller than the variance of the standardized scores. Regarding the first point, some teachers might behave differently toward low performers and potentially give them higher grades than expected by their ability. If this is the case, since girls perform worse than boys in math at the beginning of grade 6 , the gender bias estimate could partially capture a positive bias in favor of low achievers. Regarding the second element, some teachers might have a lower dispersion of their grades than the dispersion of the standardized scores. For a given dispersion of blind scores in a classroom, reducing the dispersion of non-blind scores will improve the non-blind score of the weakest in the class, relative to the scores of the best pupils. Again, since girls have initially lower scores than boys in math, a teacher who prefers a reduced dispersion of his grades will advantage girls relative to boys.

To take both effects into account, I run quantile regressions. Results in math are presented in Table A.2. The 0.5 quantile coefficient for the conditional median equals 0.308 , which is close to the DiD coefficient (0.318). However, the values for the lowest and highest deciles tend to differ more. The largest gender bias is observed in the lowest decile of the blind scores,

\footnotetext{
${ }^{32} \mathrm{~A}$ variable that controls for pupils' bad behavior is included, but girls' behavior might also affect non-blind scores through more diffuse aspects (Cornwell et al. (2013)): how they behave in the classroom, how often they answer questions, and the diligence they show in their work. I consider that these elements will not bias the results as long as they are a component of my definition of girls. In this case, the coefficient for gender bias captures some characteristics that are intrinsically linked to girls.
} 
Table A.2: QUANTILE REGRESSION COEFFICIENTS FOR THE GENDER BIAS

\begin{tabular}{|c|c|c|c|c|c|c|}
\hline \multirow[b]{2}{*}{ Dep var: B and NB Scores } & \multicolumn{5}{|c|}{ Quantile } & \multirow{2}{*}{$\begin{array}{c}\text { DiD } \\
-\end{array}$} \\
\hline & 0.1 & 0.25 & 0.5 & 0.75 & 0.9 & \\
\hline Girl x Non-Blind & $\begin{array}{c}0.299 * * * \\
(0.075)\end{array}$ & $\begin{array}{c}0.317 * * * \\
(0.068)\end{array}$ & $\begin{array}{c}0.352 * * * \\
(0.063)\end{array}$ & $\begin{array}{c}0.320 * * * \\
(0.062)\end{array}$ & $\begin{array}{c}0.280 * * * \\
(0.058)\end{array}$ & $\begin{array}{c}0.318 * * * \\
(0.027)\end{array}$ \\
\hline Girls & $\begin{array}{l}-0.060 \\
(0.043)\end{array}$ & $\begin{array}{c}-0.112^{*} \\
(0.047)\end{array}$ & $\begin{array}{c}-0.141 * * \\
(0.046)\end{array}$ & $\begin{array}{c}-0.205^{* * * *} \\
(0.048)\end{array}$ & $\begin{array}{c}-0.236 * * * \\
(0.048)\end{array}$ & $\begin{array}{c}-0.147 * * * \\
(0.026)\end{array}$ \\
\hline Non-Blind Score & $\begin{array}{c}-0.230 * * * \\
(0.046)\end{array}$ & $\begin{array}{c}-0.134 * * \\
(0.047)\end{array}$ & $\begin{array}{l}-0.084 \\
(0.045)\end{array}$ & $\begin{array}{l}-0.099 * \\
(0.042)\end{array}$ & $\begin{array}{c}-0.198 * * * \\
(0.034)\end{array}$ & $\begin{array}{c}-0.155^{* *} \\
(0.052)\end{array}$ \\
\hline Constant & $\begin{array}{l}-0.578^{*} \\
(0.264)\end{array}$ & $\begin{array}{c}0.454 \\
(0.259)\end{array}$ & $\begin{array}{c}1.368^{* * *} \\
(0.208)\end{array}$ & $\begin{array}{c}2.203^{* * * *} \\
(0.183)\end{array}$ & $\begin{array}{c}2.676 * * * \\
(0.165)\end{array}$ & $\begin{array}{l}1.255^{*} \\
(0.463)\end{array}$ \\
\hline Class FE & Yes & Yes & Yes & Yes & Yes & Yes \\
\hline $\mathrm{R} 2$ & & & & & & 0.015 \\
\hline Number of observations & 8329 & 8329 & 8329 & 8329 & 8329 & 8329 \\
\hline
\end{tabular}

${ }^{\dagger}$ Notes: All tests scores are standardized. The dependent variable is the score (both blind and non-blind) obtained by a pupil in math during the first term of grade 6 . Each pupil has two observations: one for the blind score and one for the non-blind score. Standard errors are in parentheses and have been estimated with school-level clusters. Stars correspond to the following $\mathrm{p}$-values: ${ }^{*} \mathrm{p}<.05 ; * * \mathrm{p}<.01 ; * * * \mathrm{p}<.001$.

with a coefficient of 0.327 . The smallest gender bias is observed in the highest decile of the distribution, with a coefficient of 0.272. Apart from these two values in the tails of the score distributions, the gender bias seems reasonably stable across quantiles. As a second test, I run the regression on pupils' ranks instead of pupils' test scores. Teachers' narrower or larger dispersions of their grades do not affect their pupils' rankings within class. Hence, running DiD regressions with pupils' ranks as a dependent variable is a mean to control for teachers' smaller/larger variance of grades. The results are consistent with previous conclusions: the interaction term equals -2.2 in math, meaning that girls' average rank decreases by 2.2 when they are assessed by their teacher. 


\section{Estimation of Gender Biases at the End of Grade 6}

Table A.3: Estimation OF THE GENDER BIAS - THIRD TERM

\begin{tabular}{|c|c|c|c|c|c|}
\hline & $\overline{(1)}$ & $\overline{(2)}$ & $\overline{~(3) ~}$ & $\overline{(4)}$ & $\overline{(5)}$ \\
\hline \multicolumn{6}{|l|}{ Dep var: Math scores } \\
\hline \multirow[t]{2}{*}{ Girl x Non-Blind } & $0.259 * * *$ & $0.251 * * *$ & $0.220 * * *$ & $0.251 * * *$ & $0.213^{* * *}$ \\
\hline & $(0.035)$ & $(0.041)$ & $(0.042)$ & $(0.036)$ & $(0.044)$ \\
\hline \multirow[t]{2}{*}{ Girls } & -0.045 & -0.039 & -0.106 & -0.053 & -0.108 \\
\hline & $(0.037)$ & $(0.051)$ & $(0.053)$ & $(0.036)$ & $(0.053)$ \\
\hline \multirow[t]{2}{*}{ Non-Blind Score } & -0.120 & -0.182 & -0.139 & -0.111 & -0.132 \\
\hline & $(0.069)$ & $(0.089)$ & $(0.089)$ & $(0.067)$ & $(0.088)$ \\
\hline \multicolumn{6}{|l|}{ Controls for punishment } \\
\hline \multirow[t]{2}{*}{ Punishment } & & & $-0.700 * * *$ & & $-0.683 * * *$ \\
\hline & & & $(0.050)$ & & $(0.052)$ \\
\hline \multirow{2}{*}{ Punishment $\mathrm{x}$ Non-Blind } & & & $-0.168 * *$ & & $-0.163^{* *}$ \\
\hline & & & $(0.045)$ & & $(0.043)$ \\
\hline \multirow[t]{2}{*}{ Punishment x Non-Blind x Girl } & & & 0.036 & & 0.031 \\
\hline & & & $(0.098)$ & & $(0.095)$ \\
\hline Controls for grade repetition & & & & . & . \\
\hline \multirow[t]{2}{*}{ Grade repetition } & & & & $-0.372 * * *$ & $-0.297 * *$ \\
\hline & & & & $(0.074)$ & $(0.084)$ \\
\hline \multirow[t]{2}{*}{ Repetition $\mathrm{x}$ Non-Blind } & & & & -0.119 & -0.114 \\
\hline & & & & $(0.144)$ & $(0.193)$ \\
\hline \multirow[t]{2}{*}{ Repetition x Non-Blind x Girl } & & & & 0.132 & 0.126 \\
\hline & & & & $(0.132)$ & $(0.166)$ \\
\hline \multirow[t]{2}{*}{ Constant } & $-1.398 * * *$ & $2.220 * * *$ & $1.672 * * *$ & $-1.384 * * *$ & $1.737 * * *$ \\
\hline & $(0.066)$ & $(0.125)$ & $(0.125)$ & $(0.065)$ & $(0.123)$ \\
\hline Class FE & Yes & Yes & Yes & Yes & Yes \\
\hline $\mathrm{R} 2$ & 0.122 & 0.126 & 0.181 & 0.131 & 0.188 \\
\hline Number of observations & 7714 & 4460 & 4460 & 7714 & 4460 \\
\hline
\end{tabular}

Notes: The dependent variable is the score (both blind and non-blind) obtained by a pupil in math during third term. The full sample is used in columns 1 and 4 . The sample used in columns 2,3 , and 5 does not include pupils for which a punishment variable is missing. Standard errors are in parentheses and have been estimated with school-level clusters. Stars correspond to the following $\mathrm{p}$-values: ${ }^{*} \mathrm{p}<.10 ; * * \mathrm{p}<.05 ; * * * \mathrm{p}<.01$. 


\section{Gender Bias and Teachers' Characteristics}

Contrary to prior research that finds that girls tend to benefit from discrimination in all subjects (Lindahl (2007), Lavy (2008), Robinson, Lubienski (2011), Falch, Naper (2013), Cornwell et al. (2013)), my results suggest that girls are favored in math only. To explain this difference, we should focus our attention on teacher characteristics that could influence their grading practices, specifically characteristics that would be different for math and literacy teachers (such as their gender or experience). As displayed in Table 1, the share of male and female math teachers is the same, but the pattern is very different in literacy, where 85 percent of the teachers are female. Similarly, math teachers are on average 3.5 years younger than literacy teachers.

Several studies show that the interplay between student and teacher gender plays a role in teachers' assessment (Dee (2005), Falch, Naper (2013), Lavy (2008), Ouazad, Page (2013), Lindahl (2007)). To test if teachers' genders explain their biased behavior, I run the previous DiD regressions separately on the sub-sample of male and female teachers (Graphic A.1). I find that the gender bias does not differ by teachers' gender in literature, and only marginally in math. In this subject, female teachers are less biased in favor of girls than male teachers: the average gender bias equals 0.294 for women teachers and 0.343 for male teachers, but this difference is not significant. ${ }^{33}$

Second, I test if teachers' experience affects gender bias. To do so, I decompose the sample into three groups of teachers based on their years of experience: first year, two to five years, and more than five years. This focus on the first years of experience results from the young average age of the teachers in this sample: 58.1 percent of math teachers and 45 percent of literacy teachers have five or fewer years of experience. I run the DiD regression on each of the three samples. The results suggest that, in mathematics, teachers in their first year of teaching are more biased than more experienced teachers : the average gender bias represents 0.571 points of a SD for new math teachers, versus 0.295 for teachers with more than five years of experience. In literacy, teachers' experience has no effect on their gender bias.

\footnotetext{
${ }^{33}$ My findings are in line with those of Falch and Naper (2013), who found a limited or no effect of teachers' gender on the gender bias in grades. They do not confirm Lavy (2008), whose results suggest that the gender bias in math is driven by male teachers.
} 


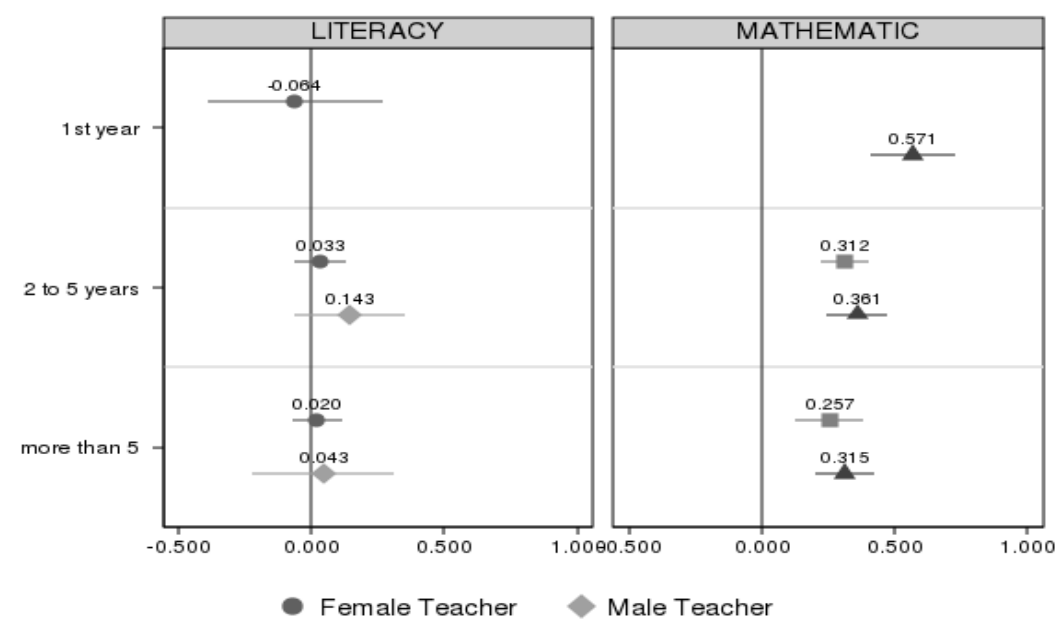

\section{E Within-Gender between-Subjects Estimation}

The following equation is used to obtain the within-gender between-subject estimate of the gender bias:

$S c o_{i n s}=\alpha_{0}+\alpha_{1} G_{i}+\alpha_{2} N B_{i}+\alpha_{3} S_{i}+\alpha_{4} G_{i} * N B_{i}+\alpha_{5} G_{i} * S_{i}+\alpha_{6} N B_{i} * S_{i}+\alpha_{7} G_{i} * N B_{i} * S_{i}+\pi_{c}+\epsilon_{\text {ins }}$

Here, $S \mathrm{Co}_{\text {ins }}$ is the grade received by a pupil when the nature of scoring is $\mathrm{n}$ ( $\mathrm{n}=1$ for nonblind and 0 for blind) and the subject is $\mathrm{s}(\mathrm{s}=1$ for math and 0 for literacy). Hence, for each pupil $i$, this dependent variable is a vector of both blind and non-blind grades received in math and literacy. $S_{i}$ corresponds to a dummy equal to 1 when the grade is given in math $(0$ in literacy). $\alpha_{7}$ is the parameter of interest: the change in the gender bias when the grade is in math rather than in literacy. Introducing the triple-interaction term $G_{i} * N B_{i} * S_{i}$ implies that $\alpha_{7}$ is estimated using only within-gender and between-subject differences. The key advantage of this identification is that it allows girls and boys to have different unobserved characteristics (response to stakes and competitiveness, behavior, etc.). $\alpha_{7}$ is identified as long as these differences do not vary across subjects. In other words, the potential correlation between the error term $\epsilon_{i n s}$ and the gender bias $G_{i} * N B_{i}$ is not problematic as long as the error term is 
independent from the difference in gender bias between subjects-the triple-interaction term. Results are presented below and commented on directly in the paper.

Table A.4: Estimation OF THE GENDER BIAS USING TRIPLE DIFFERENCES

\begin{tabular}{lc}
\hline \hline Girls x Non-Blind x Math & $0.291^{* * *}$ \\
& $(0.037)$ \\
Girls & $0.426^{* * *}$ \\
& $(0.019)$ \\
Math & $0.281^{* * *}$ \\
& $(0.027)$ \\
Non-Blind Score & -0.010 \\
& $(0.044)$ \\
Girls x Non-Blind & 0.027 \\
& $(0.032)$ \\
Girls x Math & $-0.580^{* * *}$ \\
& $(0.019)$ \\
Non-Blind x Math & $-0.146^{* *}$ \\
& $(0.047)$ \\
Constant & $1.470^{* * *}$ \\
& $(0.151)$ \\
Class FE & Yes \\
\hline R2 & 0.116 \\
Number of observations & 16644 \\
\hline \hline
\end{tabular}

Notes: The dependent variable is the score, both blind and non-blind, obtained by a pupil in math and in literacy. Standard errors are in parentheses and have been estimated with school-level clusters. Stars correspond to the following $\mathrm{p}$ values: $* \mathrm{p}<.05 ; * * \mathrm{p}<.01 ; * * * \mathrm{p}<.001$.

\section{F Correlation between the Skills Measured by the Blind and} the Non-Blind Scores

In mathematical terms, the assumption that both tests measure the same ability is equivalent to $\rho=1$ and $v_{i}=0$ in Equation 14 defined in section VI.A: $\theta_{2 i}=\rho \theta_{1 i}+v_{i}$. If we relax this 
hypothesis, we are back to the reduced-form equation presented previously:

$$
N B_{i}=\alpha_{0}+\rho B_{i}+\alpha_{2} G_{i}+\left(\epsilon_{i N B}+v_{i}-\rho \epsilon_{i B}\right)
$$

A way to test the validity of the hypothesis is to directly estimate the reduced-form equation above and to verify if the coefficient $\rho$ is significantly different from 1 . If not, both tests can be assumed to measure abilities that are very similar, and DiD estimates can safely be assumed to be unbiased. ${ }^{34}$ However, to correctly estimate the parameter $\rho$ in this equation, I have to get rid of the measurement error bias. Since $B_{i}$ is a noisy measure of ability $\theta_{1 i}$, it is correlated to the measurement error $\epsilon_{i B}$. I solve this endogeneity issue by instrumenting $B_{i}$. A pupil's month of birth is used as an instrument that is correlated to his/her blind score but is independent from the error term.

In the literature, students' months of birth have been shown to be an important determinant of pupils' success at school (Angrist, Krueger (1991), Bedard, Dhuey (2006), Crawford et al. (2007)). I test the correlation between blind scores and pupils' months of birth by running a regression of blind scores in literacy and math on a set of 11 dummies for each month of birth. January is taken as the reference month so that all coefficients should be interpreted relatively to this month. Figure A.2 presents the correlation coefficients.

\footnotetext{
${ }^{34}$ I will discuss in a further section an additional assumption required for the DiD to be unbiased. Although we cannot test whether $v_{i}=0$, the term $v_{i}$ should be equally distributed between boys and girls.
} 
Figure A.2:

CORRELATION BETWEEN PUPILS' MONTHS OF BIRTH AND THE BLIND SCORE

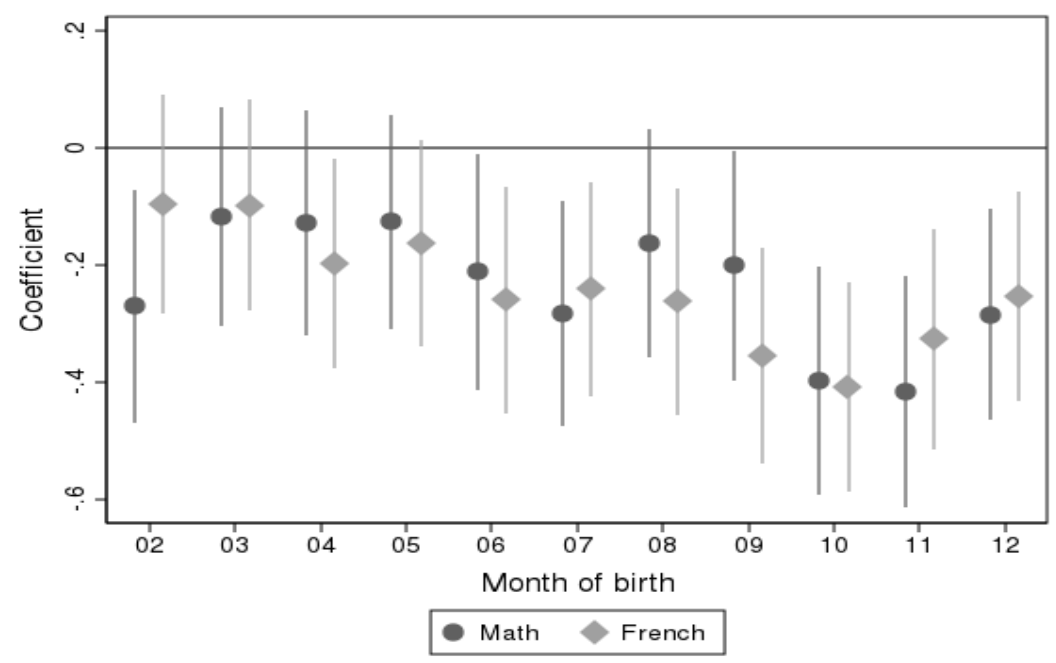

There is clear evidence that pupils born at the end of the year have lower results than those born at the beginning of the year. From this observation, and to avoid including too many instrumental variables in the equation, I create a dummy variable for pupils born after July. Results of the first-stage regression are displayed in Table A.5. Once controlled for covariates, being born at the end of the year has an important negative effect on blind scores -0.150 points of the SD in math and 0.173 in literacy. The F-stat reported at the bottom of the table corresponds to the stat obtained when the blind score is regressed on the instrument only.

Being born at the end of the year will be a valid instrument if the following exclusion restriction holds: the only reason why a pupil's month of birth affects teachers' grades is because being born at the end of the year impacts his ability — measured by the blind score-once controlled for other covariates. In other words, being born at the end of the year is uncorrelated to the random shocks that enter the error term of Equation (5): $\epsilon_{i N B}+v_{i}-\rho \epsilon_{i B}$. I claim that this restriction is valid, provided that I control for pupils' behavior, parents' professions, and grade retention, three variables that might be correlated to being born at the end of the year. ${ }^{35}$ The reduced-form Equation 15 is estimated, first with standard OLS, and second by instrumenting

\footnotetext{
${ }^{35}$ Buckles, Hungerman (2012) showed that family background characteristics have strong relations with both season of birth and later educational outcomes.
} 
Table A.5: FIRST STAGE - CORRELATION

BETWEEN BLIND SCORE AND BEING BORN AT

THE END OF THE YEAR

\begin{tabular}{lcc}
\hline \hline & Math & Literacy \\
Dep var : Blind score & & \\
\hline Born End of Year & $-0.150^{* * *}$ & $-0.173^{* * *}$ \\
& $(0.041)$ & $(0.040)$ \\
Girl & $-0.177^{* * *}$ & $0.386^{* * *}$ \\
& $(0.042)$ & $(0.041)$ \\
Punishment & $-0.469^{* * *}$ & $-0.522^{* * *}$ \\
& $(0.071)$ & $(0.067)$ \\
Grade repetition & $-0.323^{* *}$ & $-0.204^{*}$ \\
& $(0.099)$ & $(0.082)$ \\
High SES & $0.410^{* * *}$ & $0.412^{* * *}$ \\
& $(0.055)$ & $(0.053)$ \\
Constant & $0.137 * * *$ & $-0.149 * * *$ \\
& $(0.039)$ & $(0.038)$ \\
\hline R2 & 0.060 & 0.112 \\
Number of observations & 2175 & 2127 \\
F stat & 14.12 & 18.01 \\
\hline \hline
\end{tabular}

Notes: The dependent variable is the blind score obtained by a pupil during the first term of grade 6 . Standard errors are in parentheses and have been estimated with schoollevel clusters. Stars correspond to the following $\mathrm{p}$-values: $* \mathrm{p}<.05 ; * * \mathrm{p}<.01 ; * * * \mathrm{p}<.001$. All tests scores are standardized.

the blind score. Results are presented in Table A.6 and commented on directly in the paper. ${ }^{36}$

\footnotetext{
${ }^{36}$ As previously, all regressions include class fixed effects. They are run on a sample that contains 2175 pupils in math and 2127 pupils in literacy for which the blind score, non-blind score, and punishment variable are not missing. Standard errors are estimated with school-level clusters to take into account common shocks at the school level.
} 
Table A.6:

OLS AND IV ESTIMATES OF THE REDUCED FORM

\begin{tabular}{lccccc}
\hline \hline & \multicolumn{2}{c}{ OLS } & & \multicolumn{2}{c}{ IV } \\
\cline { 2 - 3 } \cline { 5 - 6 } Dep var : Non-Blind score & Math & Literacy & & Math & Literacy \\
\hline Blind score & & & & \\
& $0.760^{* * * *}$ & $0.684^{* * *}$ & & $1.090^{* * *}$ & $0.964^{* * *}$ \\
Girl & $(0.019)$ & $(0.031)$ & & $(0.100)$ & $(0.099)$ \\
& $0.264^{* * *}$ & $0.172^{* * *}$ & & $0.339^{* * *}$ & 0.080 \\
Constant & $(0.028)$ & $(0.043)$ & & $(0.032)$ & $(0.057)$ \\
& $-4.794^{* * *}$ & $-9.031^{* * *}$ & $-7.617^{* * *}$ & $-11.585^{* * *}$ \\
Class FE & $(0.190)$ & $(0.309)$ & & $(0.846)$ & $(0.896)$ \\
Controls & Yes & Yes & & Yes & Yes \\
\hline R2 & Yes & Yes & & Yes & Yes \\
Number of observations & 0.687 & 0.607 & & 0.594 & 0.549 \\
p-val(Blind=1) & 2175 & 2127 & & 2175 & 2127 \\
\hline \hline
\end{tabular}

Notes: Standard errors are in parentheses and have been estimated with school-level clusters. Stars correspond to the following $\mathrm{p}$-values : * $\mathrm{p}<.05 ; * * \mathrm{p}<.01 ; * * * \mathrm{p}<.001$. The unit of observation is a pupil. The sample contains 2175 pupils in math and 2127 pupils in literacy for which the blind score, non-blind score, and punishment variable are not missing. The instrument is a dummy variable equal to 1 if a pupil is born between July and December. Control variables included: grade repetition, punishment, and high SES.

Finally, regarding the exclusion restriction, some might argue that, once controlled for the abilities measured by the blind score, being born at the end of the year is not perfectly independent from unobserved specific skills $v_{i}$ tested by the non-blind score only. If this is the case, it is likely that being born at the end of the year would also be negatively correlated with these unobserved skills. Therefore, the IV estimates of $\rho$ might be an upper bound for the true value of $\rho$, while the OLS would be a lower bound (due to the downward measurement error bias). Indeed, the IV estimate is $\rho_{I V}=\frac{\operatorname{Cov}\left(N B_{i}, \text { EndYear }_{i}\right)}{\operatorname{Cov}\left(B_{i}, \text { EndYear }_{i}\right)}$. If a correlation exists between $v_{i}$ and being born at the end of the year, this would affect the numerator of the formula by increasing $\operatorname{Cov}\left(N B_{i}\right.$, EndYear $\left.i\right)$. Hence $\rho_{I V}$ would be an upper bound for the parameter $\rho$. 